\title{
Some statistical aspects of the monitoring of GM plants
}

\author{
Joe N. Perry
}

Oaklands Barn, Lug's Lane, Broome, Norfolk NR35 2HT, United Kingdom

joe.perry@bbsrc.ac.uk

This paper will focus on spatial heterogeneity, temporal heterogeneity and spatio-temporal heterogeneity 


\section{VDI 4330}

Monitoring the effects of genetically modified organisms (GMO)

\section{Standardised monitoring of butterflies and moths}

(Lepidoptera)

Transect method, light trap, and larval survey

- illustrate spatio-functional environmental fea-tures due to their mobility and often complex habitat requirements [19],

- are therefore particularly suitable for landscapelevel monitoring as well [20] and

- via the spatio-temporal availability of subhabitats 


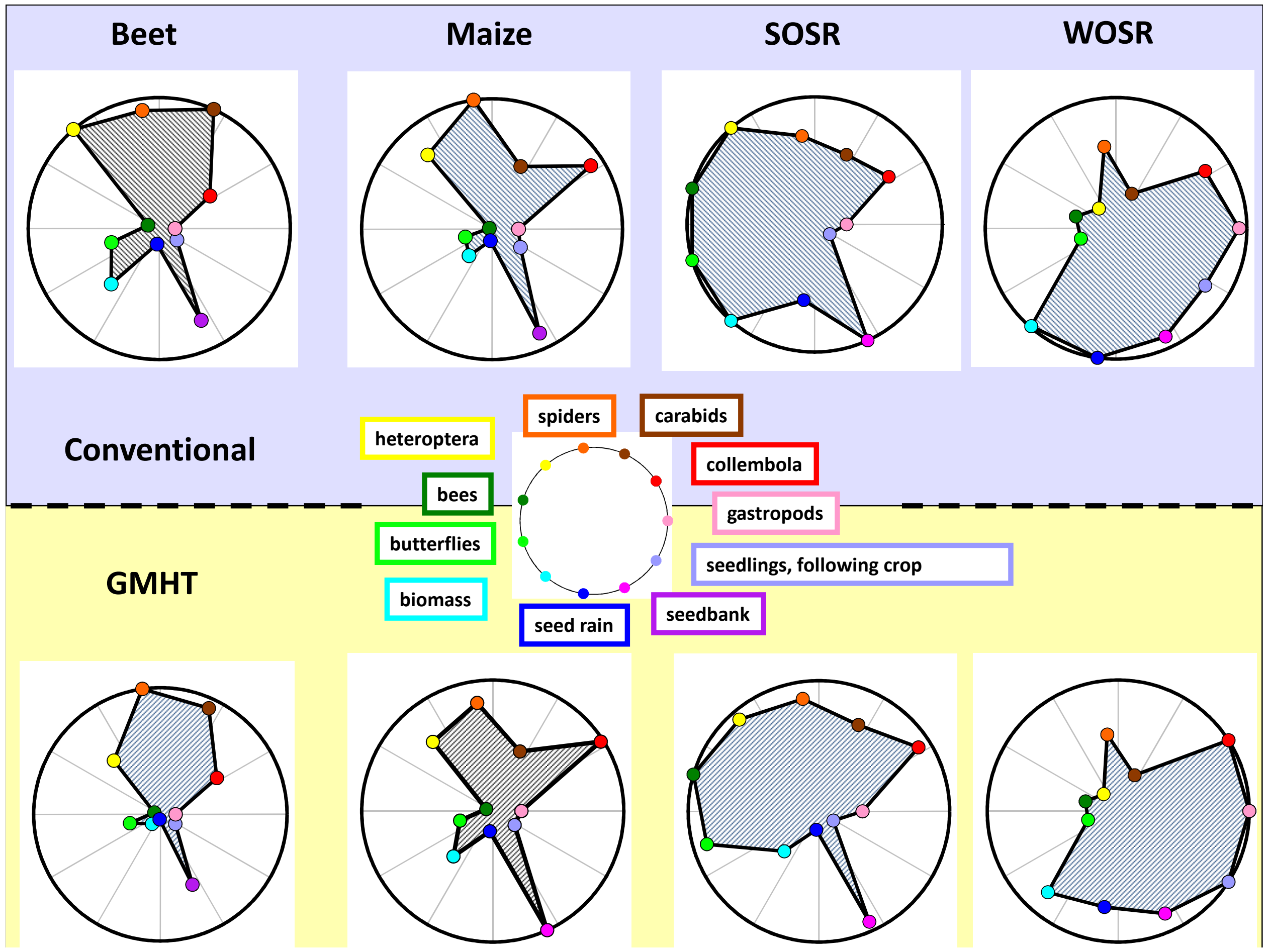




$\begin{array}{ll}\text { Treatment } & \text { Crop } \\ \text { - conventional } & \text { SOSR } \\ \text { O GMHT } & \text { WOSR }\end{array}$

Maize

Beet

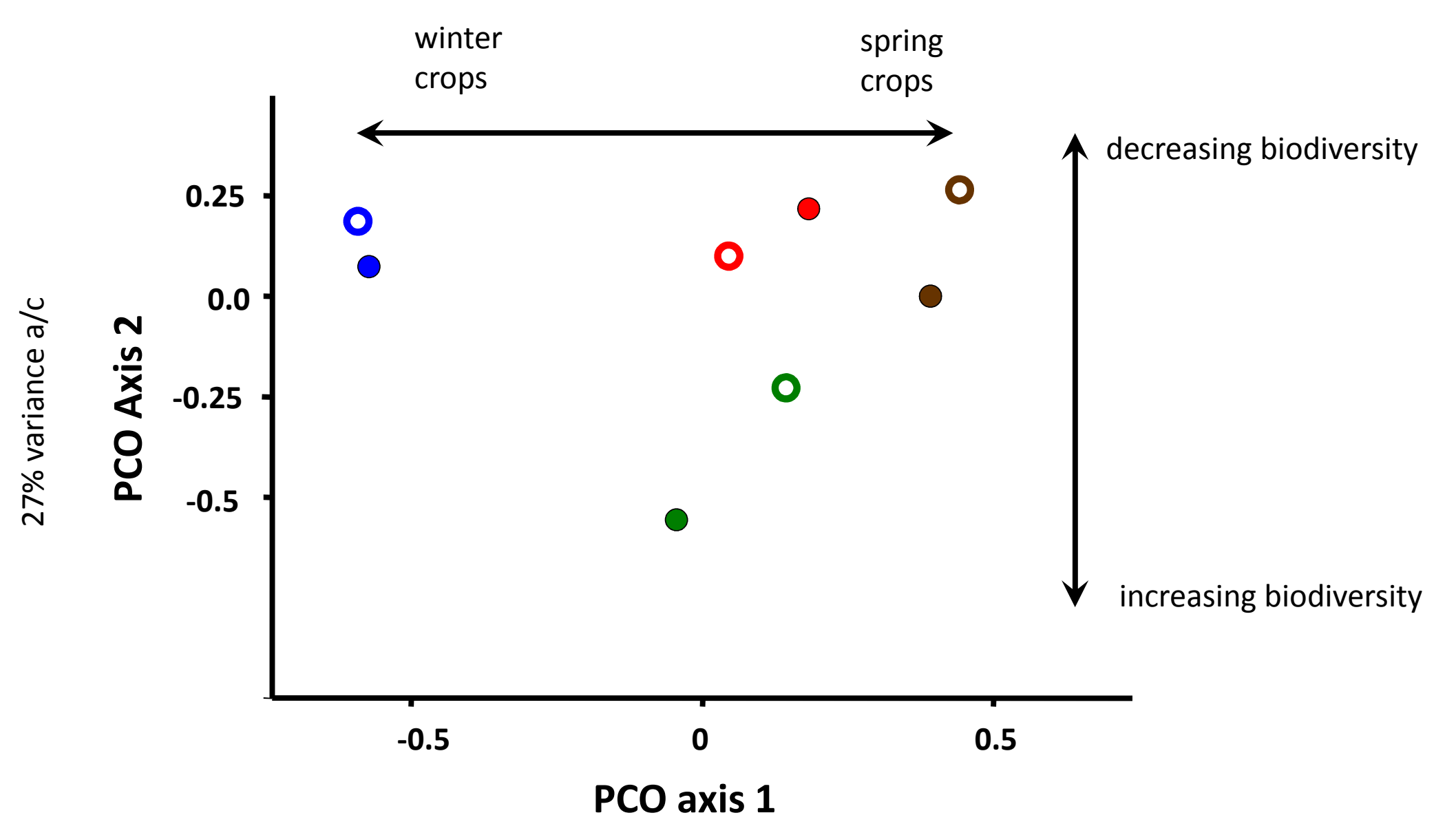

$58 \%$ variance a/c 


\section{Heard MS, Rothery P, Perry JN \& Firbank LG (2005) ]}

Predicting longer-term changes in weed populations under GMHT crop management.

\section{Weed Research, 45, 331-338.}

Context for this paper:

Heard et al (2003b) predicted from FSE results that seedbank decline might increase from $3 \%$ per annum to $10 \%$.

\section{But this would all depend} on the rotation.
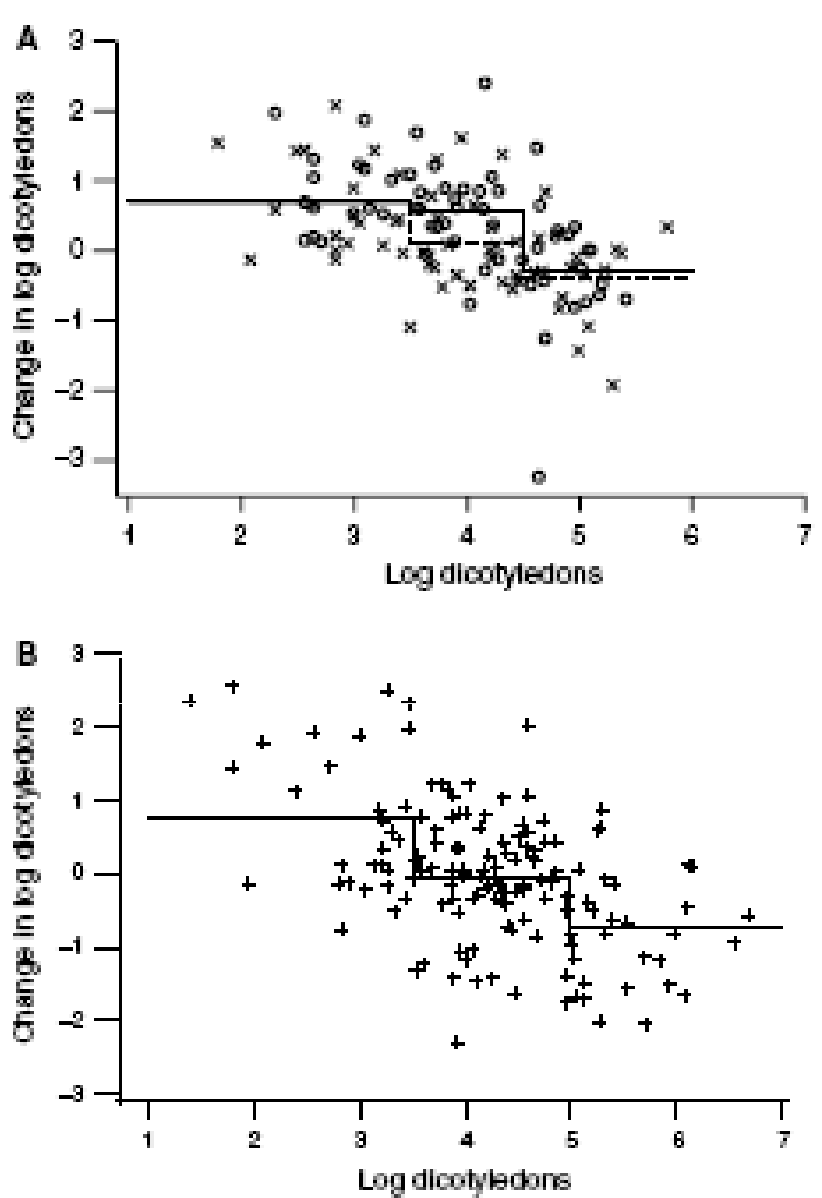

Fig. 1 Illwtration of model for seed hunk density dependence. (A) For beet in break crop, the change in logarithmically trans formed fcotyledon seed count, $D(t+1)-D(t)$ is plotted against initia logarithmically transformed dootyledon seed count, $D(t)$. (B) In following cereal crop $D(t+2)-D(t+1)$ is plotred against $D(t+1)$. Lines show mean values of change in $D$ over different ranges of initial values of $D$ (see Table 2 ) for the two treatment: comentional (open circles, solid lines); GMHT (crosses, dashed line). In the following cereal crop there were no dfferences between treatments. 
$\mathbf{A}$

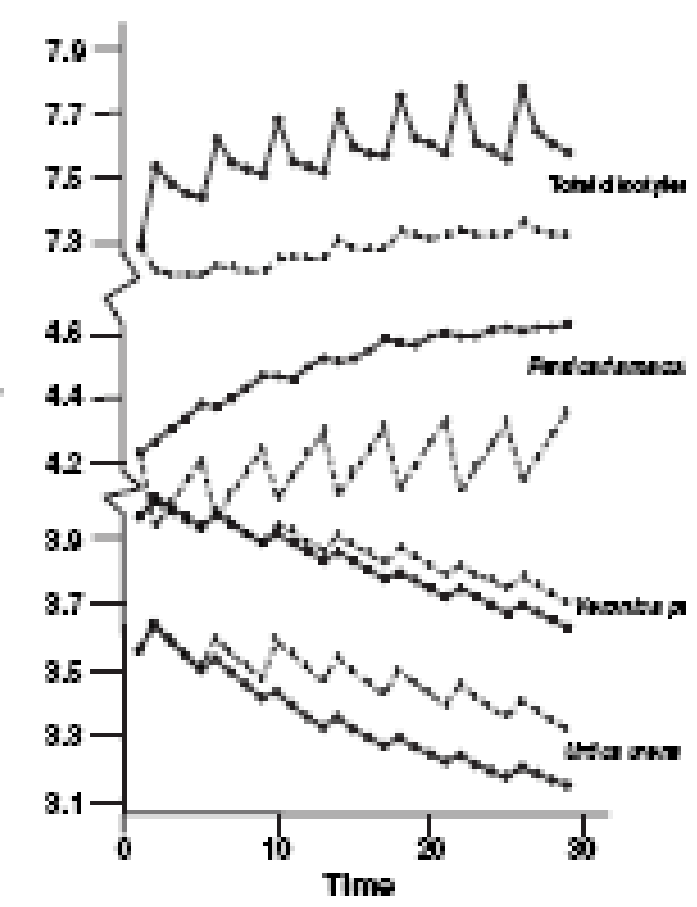

B

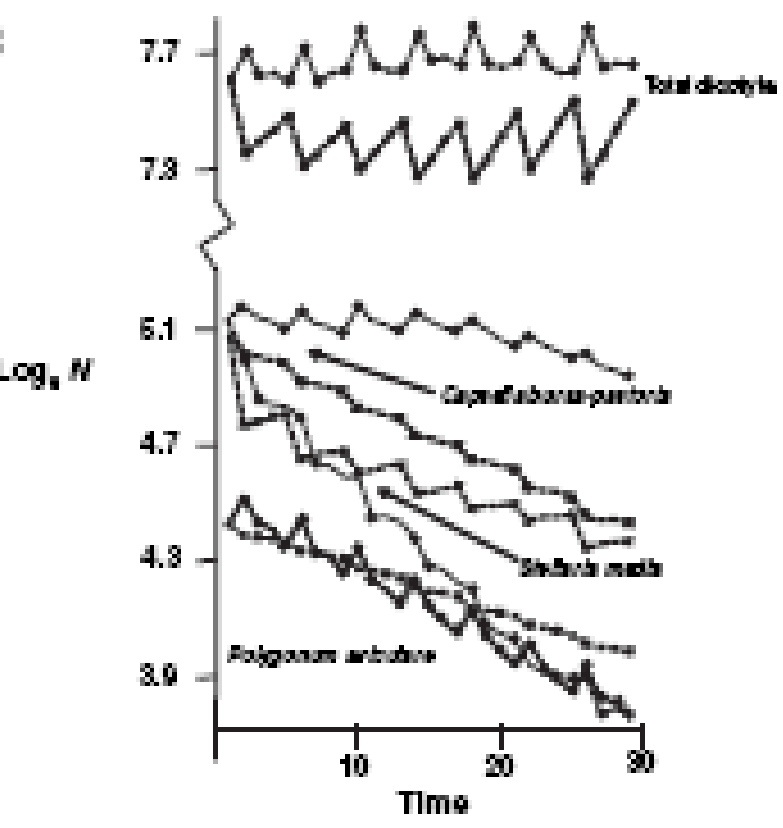

C

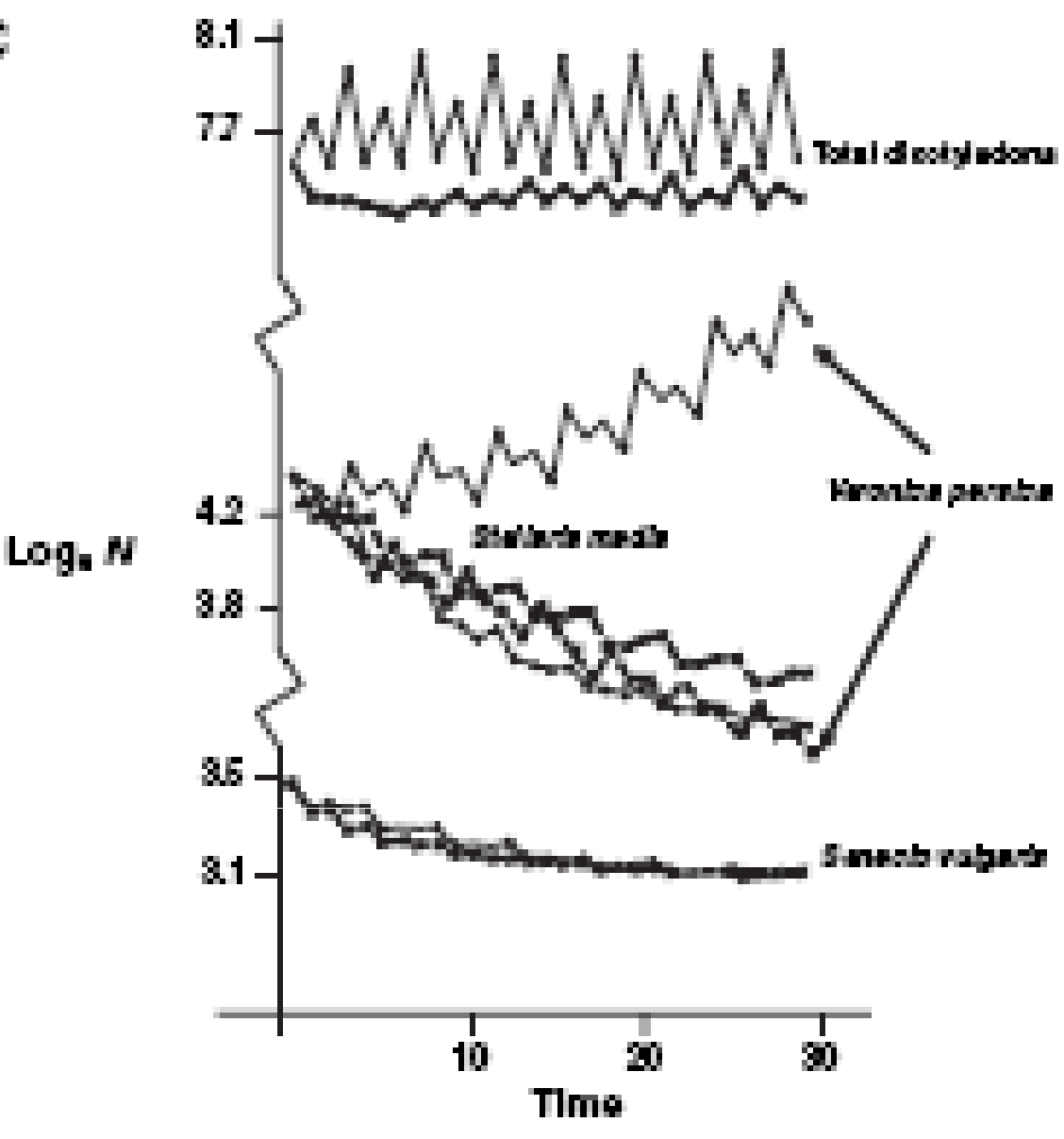

Fly 2 Model propection of $\log N$ mein loginthmically tranfarmot protictat seat huk density, for comentional folid circhi) and GMHT mangement (crowes) in 4 year rotations, plotted agoinet time, in years. (A) Beet, cereal, oreal, cereal, (B) spring rape, cereal, ored, cereal, (C) bot, cereal, spring rape, oreal. Protictors of sed derity areshown for intuidul apecies

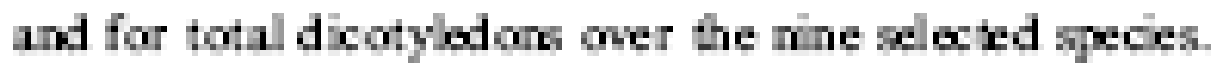




\section{Crop Rotations : Survey results from Selommes, Burgundy}

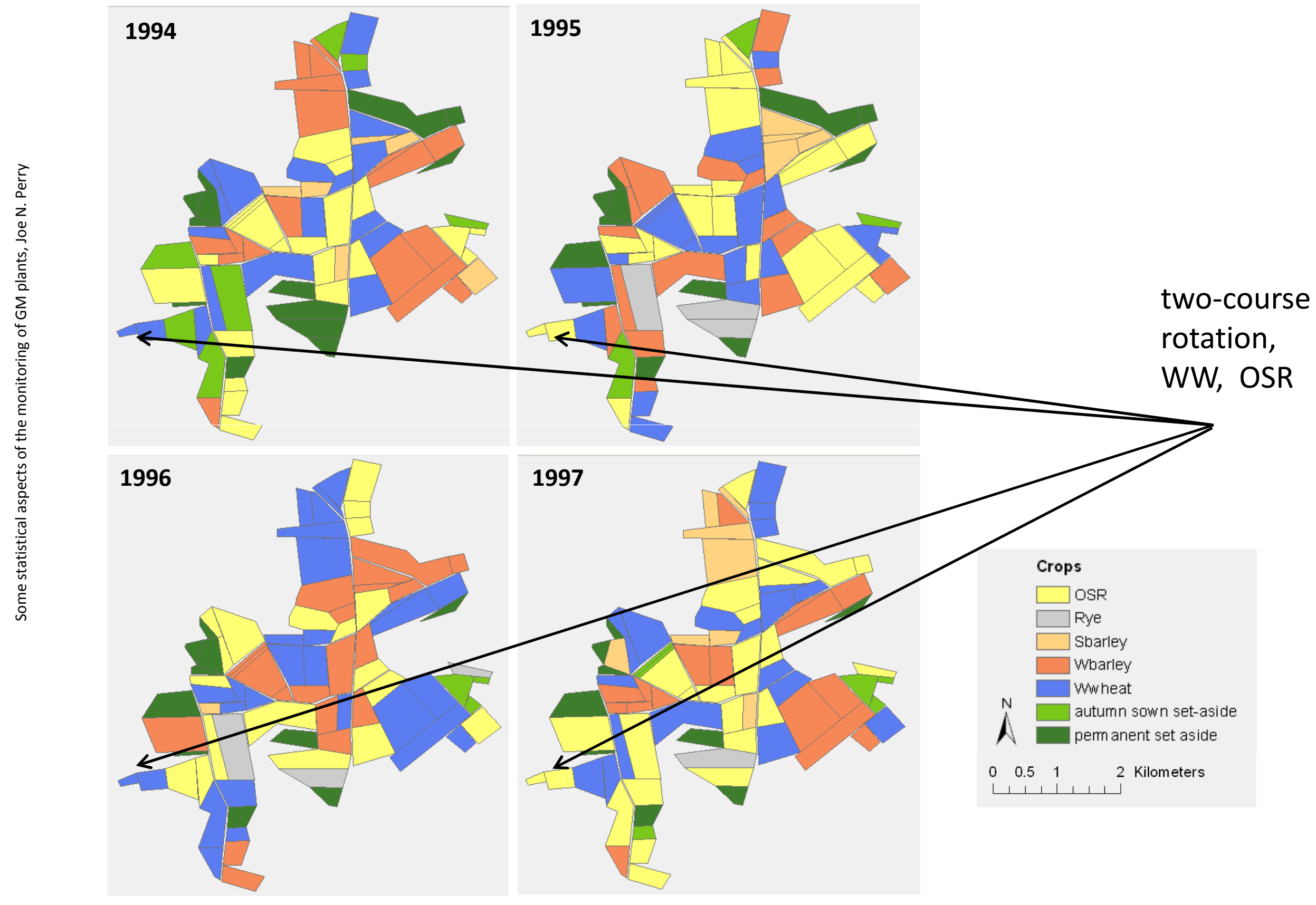




\section{Different rotations in Selommes landscape, with differing lengths}

\begin{tabular}{|c|c|c|c|c|c|c|c|}
\hline \multirow{2}{*}{$\begin{array}{c}\text { Rotation } \\
\text { ID }\end{array}$} & \multicolumn{6}{|c|}{ Years in rotations } & \multirow{2}{*}{$\begin{array}{l}\text { Rotatior } \\
\text { Length }\end{array}$} \\
\hline & 0 & 1 & 2 & 3 & 4 & 5 & \\
\hline \multirow{5}{*}{ 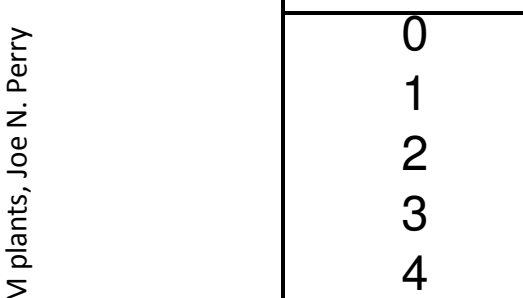 } & sa & & & & & & 1 \\
\hline & W & OSR & & & & & 2 \\
\hline & W & OSR & $\mathrm{Wb}$ & & & & 3 \\
\hline & W & Wb & OSR & & & & 3 \\
\hline & W & $\mathrm{Sb}$ & OSR & & & & 3 \\
\hline \multirow{5}{*}{ 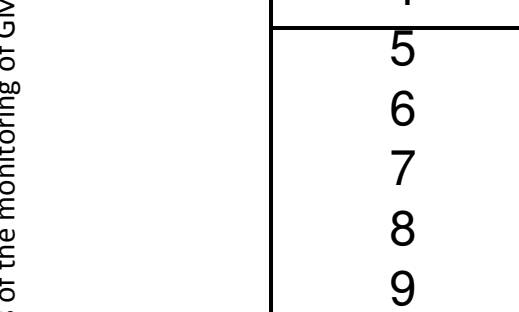 } & W & $\mathrm{Sb}$ & $\mathrm{Wb}$ & OSR & & & 4 \\
\hline & W & $\mathrm{Wb}$ & $\mathrm{Sb}$ & $\mathrm{Sb}$ & $\mathrm{Wb}$ & & 5 \\
\hline & W & W & OSR & W & $\mathrm{Wb}$ & OSR & 6 \\
\hline & W & Wb & OSR & W & $\mathrm{Sb}$ & OSR & 6 \\
\hline & W & $\mathrm{Wb}$ & OSR & W & $\mathrm{Wb}$ & sa & 6 \\
\hline & W & OSR & Wb & W & $\mathrm{sa}$ & Wb & 6 \\
\hline & W & $\mathrm{Sb}$ & $\mathrm{Wb}$ & OSR & $\mathrm{Wb}$ & OSR & 6 \\
\hline & W & OSR & W & OSR & W & sa & 6 \\
\hline & W & OSR & W & OSR & sa & sa & 6 \\
\hline & W & OSR & sa & sa & sa & sa & 6 \\
\hline & $\mathrm{Wb}$ & OSR & $\mathrm{sa}$ & $\mathrm{sa}$ & $\mathrm{sa}$ & sa & 6 \\
\hline & $\mathrm{Sb}$ & sa & sa & sa & sa & sa & 6 \\
\hline & $\mathrm{R}$ & OSR & $\mathrm{R}$ & sa & sa & sa & 6 \\
\hline & $\mathrm{R}$ & $\mathrm{R}$ & OSR & sa & sa & sa & 6 \\
\hline & W & W & sa & sa & $\mathrm{R}$ & OSR & 6 \\
\hline 20 & W & sa & sa & $\mathrm{Sb}$ & $\mathrm{Wb}$ & OSR & 6 \\
\hline
\end{tabular}

$66.7 \%$ of rotations have a 6 years length $80.98 \%$ of rotations have a length that is a multiple of 3 years 


\section{A taxonomy of crop rotations (1)}

\section{Various types of crop rotation}

1) pre-defined, fixed crop rotation

(example from Dijon \& Selommes)

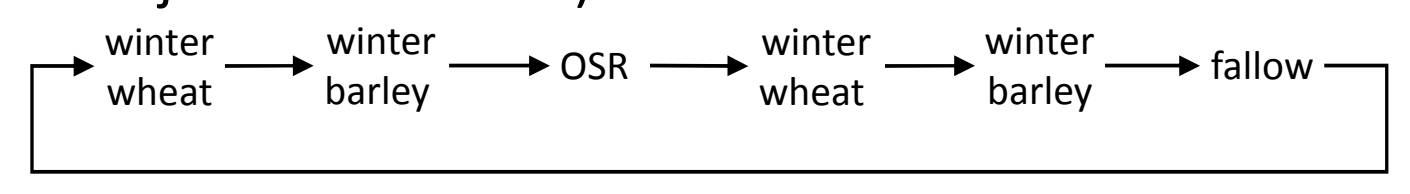

Cyclical, fixed length

here six years 


\section{A taxonomy of crop rotations (2)}

1) pre-defined, fixed crop rotation

(another example from south-east England)

$\rightarrow$ sugar beet $\rightarrow$ fallow $\rightarrow$ wheat $\rightarrow$ OSR $\rightarrow$ wheat $\rightarrow$

Cyclical, fixed length, here five years

2) flexible crop rotations

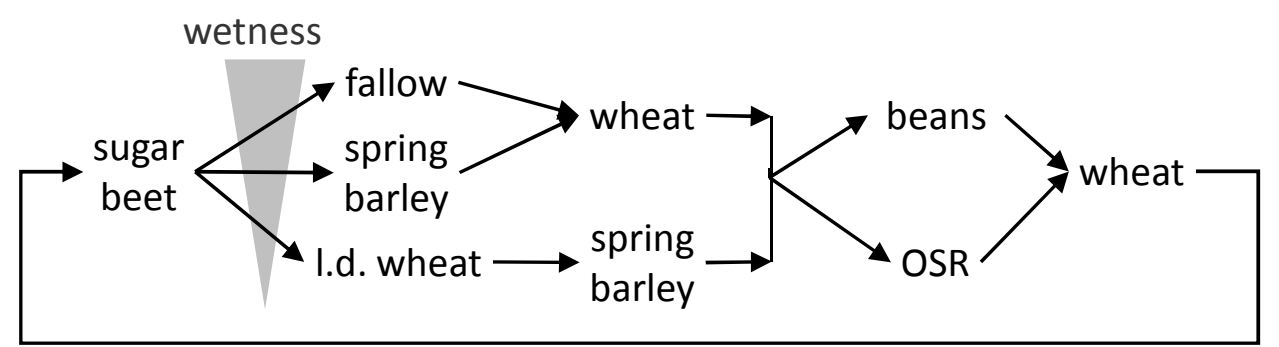

Stochastic, multi-pathway, cyclical, fixed length, here five years 


\section{A taxonomy of crop rotations (3)}

\section{In what sense 'Stochastic'?}

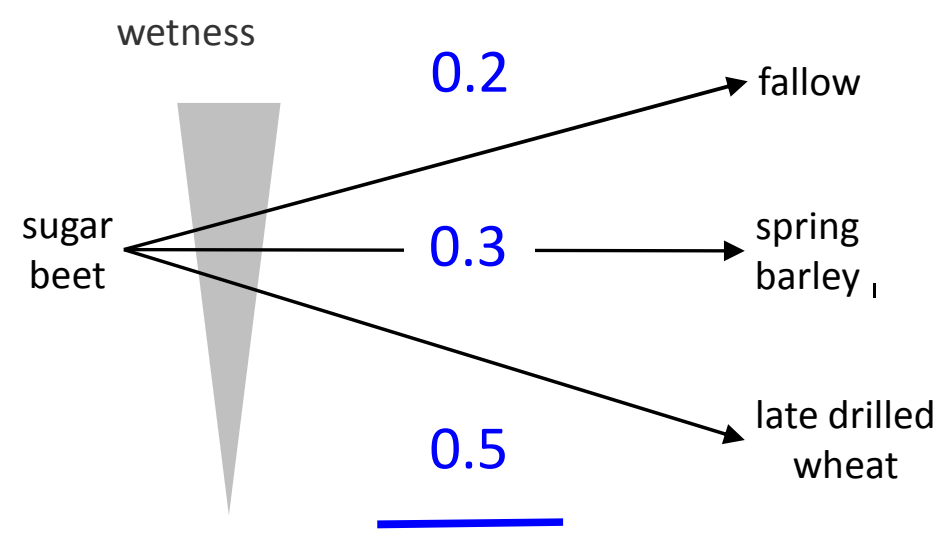

$$
1.0
$$

probabilities, sum to unity

not decided by random choice of the farmer

determined by events that are themselves governed by chance and whose long-term chance of occurring may be estimated 


\section{A taxonomy of crop rotations (4)}

\section{3) flexible crop rotations}

Stochastic, multi-pathway, cyclical, variable length;

return period to the second wheat may be four, five, nine, , , years, etc

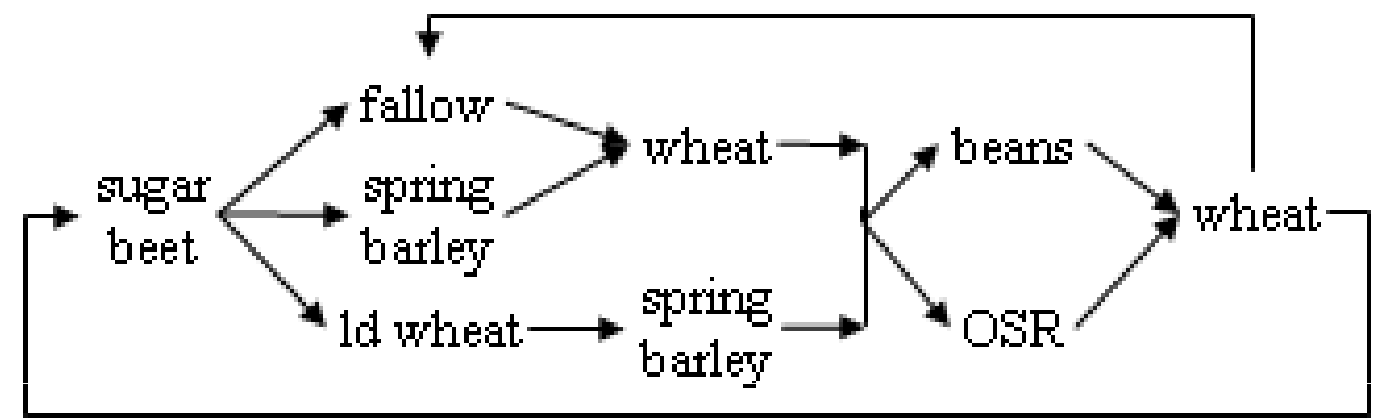

\section{4) Less structured crop rotations}

Highly flexible, exponentially multi-pathway, cyclical but with undefined length

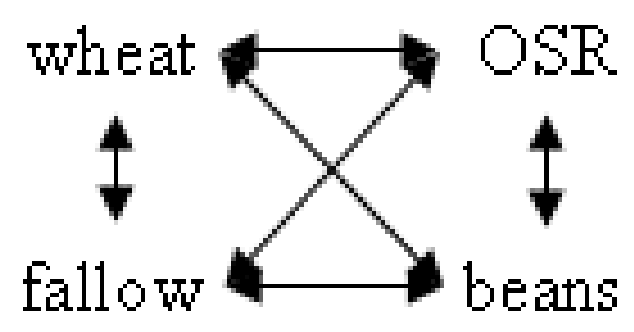




\section{Representation of rotations within software (2)}

\section{Most rotations may be represented by a transition matrix .....}

\begin{tabular}{|c|c|c|c|c|c|c|}
\hline & & \multicolumn{5}{|c|}{ Current year } \\
\hline \multirow{6}{*}{$\begin{array}{l}\text { Previous } \\
\text { year }\end{array}$} & & $\begin{array}{c}\text { Sugar } \\
\text { beet }\end{array}$ & Fallow & $\begin{array}{c}\text { First } \\
\text { wheat }\end{array}$ & OSR & $\begin{array}{l}\text { Second } \\
\text { wheat }\end{array}$ \\
\hline & Sugar beet & 0 & 1 & 0 & 0 & 0 \\
\hline & Fallow & 0 & 0 & 1 & 0 & 0 \\
\hline & First wheat & 0 & 0 & 0 & 1 & 0 \\
\hline & Oilseed rape (OSR) & 0 & 0 & 0 & 0 & 1 \\
\hline & Second wheat & 1 & 0 & 0 & 0 & 0 \\
\hline
\end{tabular}

... in which the probabilities of going from a crop in one year to a crop in the next year are represented numerically 


\section{Representation of rotations within software (2)}

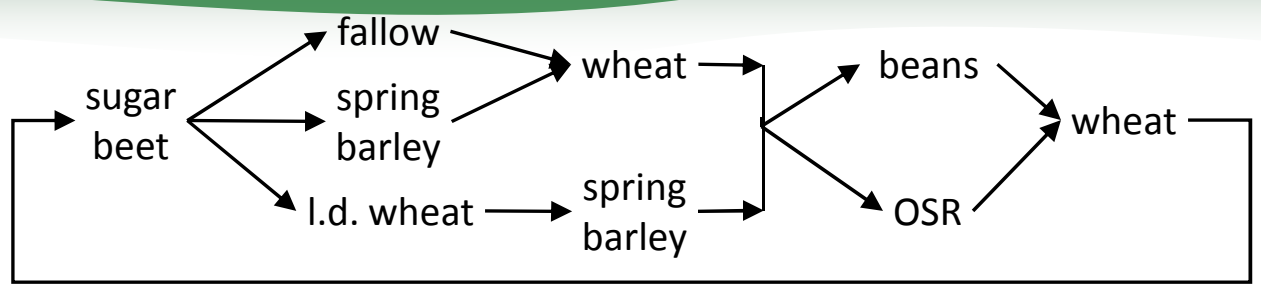

\begin{tabular}{|c|c|c|c|c|c|c|c|c|c|c|}
\hline & & \multicolumn{9}{|c|}{ Current year } \\
\hline \multirow{10}{*}{$\begin{array}{l}\text { Previous } \\
\text { year }\end{array}$} & & S. beet & Fallow & $\begin{array}{c}1^{\text {st }} \mathrm{S} . \\
\text { barley }\end{array}$ & $\begin{array}{c}\text { I.d. } \\
\text { wheat }\end{array}$ & $\begin{array}{c}1^{\text {st }} \\
\text { wheat }\end{array}$ & $\begin{array}{l}2^{\text {nd }} \mathrm{S} . \\
\text { barley }\end{array}$ & Beans & OSR & $\begin{array}{c}2^{\text {nd }} \\
\text { wheat }\end{array}$ \\
\hline & S. beet & 0 & 0.3 & 0.35 & 0.35 & 0 & 0 & 0 & 0 & 0 \\
\hline & Fallow & 0 & 0 & 0 & 0 & 1 & 0 & 0 & 0 & 0 \\
\hline & $1^{\text {st }} \mathrm{S}$. barley & 0 & 0 & 0 & 0 & 1 & 0 & 0 & 0 & 0 \\
\hline & I.d. wheat & 0 & 0 & 0 & 0 & 0 & 1 & 0 & 0 & 0 \\
\hline & $1^{\text {st }}$ wheat & 0 & 0 & 0 & 0 & 0 & 0 & 0.5 & 0.5 & 0 \\
\hline & $2^{\text {nd }}$ S. barley & 0 & 0 & 0 & 0 & 0 & 0 & 0.5 & 0.5 & 0 \\
\hline & Beans & 0 & 0 & 0 & 0 & 0 & 0 & 0 & 0 & 1 \\
\hline & OSR & 0 & 0 & 0 & 0 & 0 & 0 & 0 & 0 & 1 \\
\hline & $2^{\text {nd }}$ wheat & 1 & 0 & 0 & 0 & 0 & 0 & 0 & 0 & 0 \\
\hline
\end{tabular}

Transition matrices:

square matrix

entries are probabilities

exactly equal to 0 or 1 if fixed; between $0 \& 1$ if stochastic sum of each row $=1$ 


\section{Need to estimate proportions of crops}

want to be able to estimate long-term proportion of each crop grown within a rotation
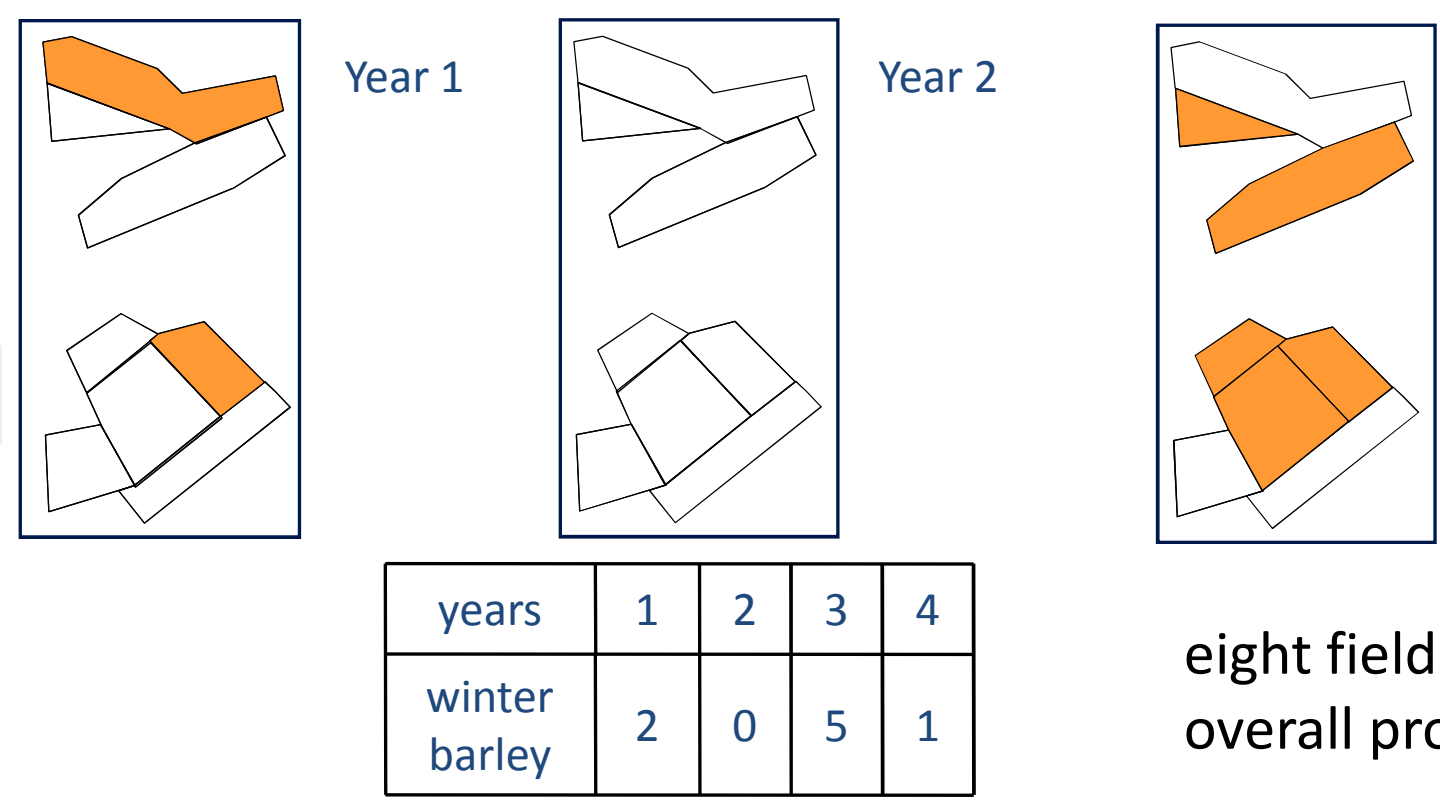

Year 3

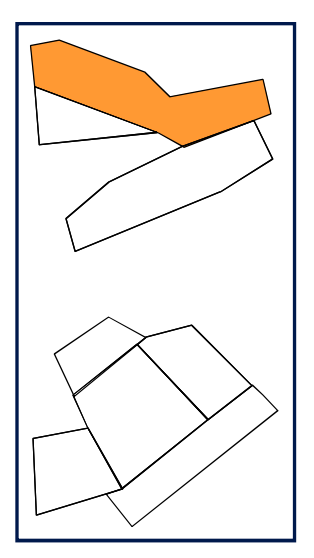

Year 4

eight fields, four years

overall proportion of winter barley $=0.25$ 


\section{Calculation of long-term average crop proportions (1)}

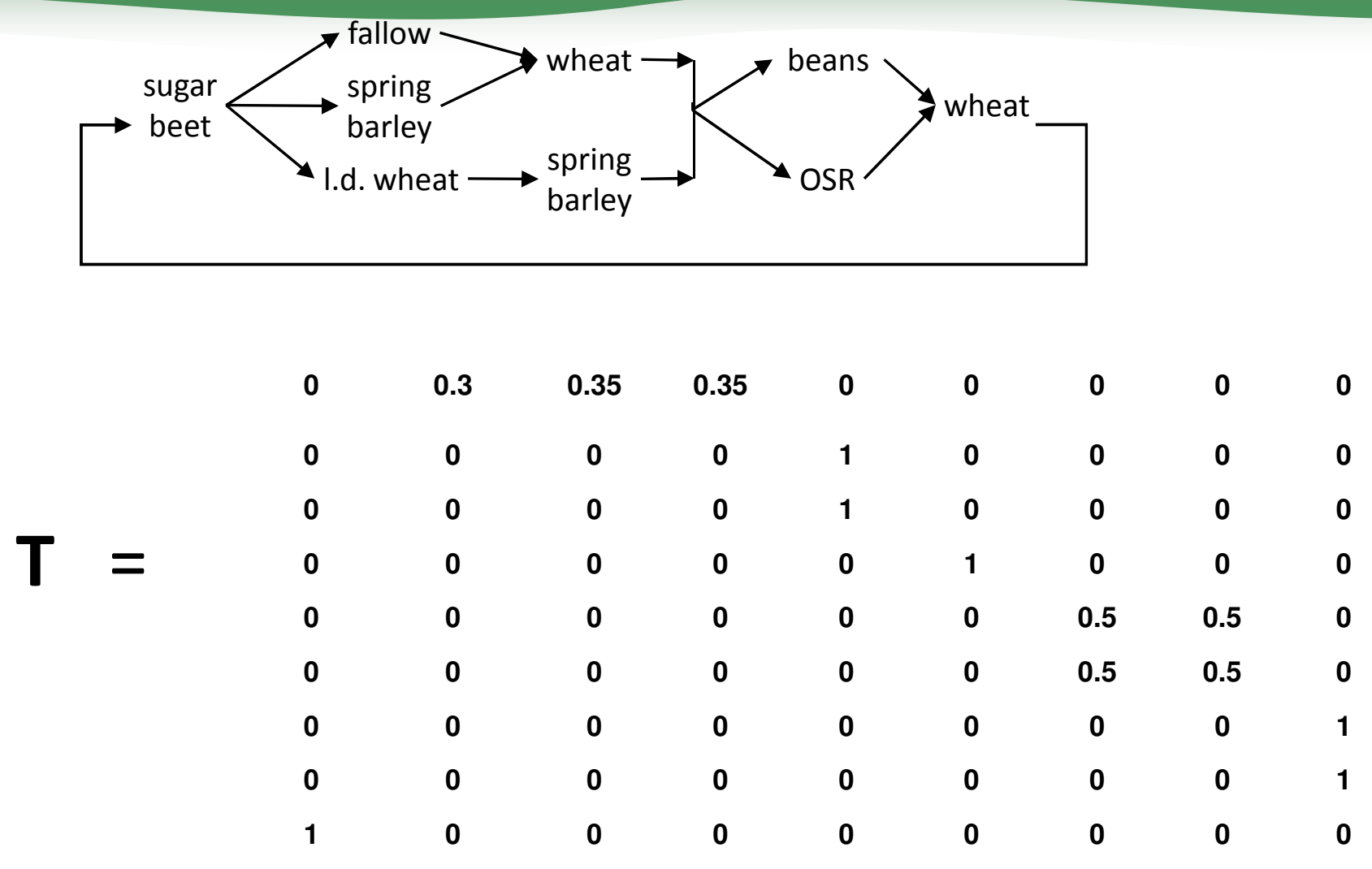

Pre-multiply the transition matrix $\mathbf{T}$ by itself many times

Obtain a new matrix $\mathbf{T}(\mathbf{n})$, where $\mathbf{T}(\mathbf{n})=\mathbf{T} \times \mathbf{T}(\mathbf{n}-\mathbf{1})=\mathbf{T}^{\mathrm{n}-1} \times \mathbf{T}=\mathbf{T}^{\mathrm{n}}$

$\mathbf{T}(\mathbf{n})$ converges as $n$ increases and the elements in any column become ever more similar The average of the $j$ th column represents the long-term average proportion of the $j$ th crop 


\section{Calculation of long-term average crop proportions (2)}

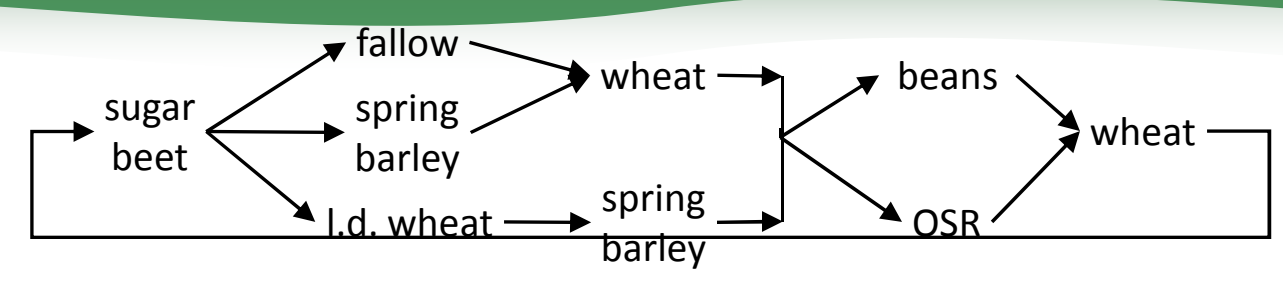

\begin{tabular}{|c|c|c|c|c|c|c|c|c|}
\hline $\begin{array}{c}\text { S. } \\
\text { Beet }\end{array}$ & Fallow & $\begin{array}{c}1^{\text {st }} \text { S. } \\
\text { barley }\end{array}$ & $\begin{array}{c}\text { I.d. } \\
\text { wheat }\end{array}$ & $\begin{array}{c}1^{\text {st }} \\
\text { wheat }\end{array}$ & $\begin{array}{c}2^{\text {nd }} \text { S. } \\
\text { barley }\end{array}$ & Beans & OSR & $\begin{array}{c}2^{\text {nd }} \\
\text { wheat }\end{array}$ \\
\hline 0.2 & 0.06 & 0.07 & 0.07 & 0.13 & 0.07 & 0.1 & 0.1 & 0.2
\end{tabular}

\begin{tabular}{|c|c|c|c|c|c|c|c|c|c|}
\hline & 0.2 & 0.06 & 0.07 & 0.07 & 0.13 & 0.07 & 0.1 & 0.1 & 0.2 \\
\hline$n=$ & 0.2 & 0.06 & 0.07 & 0.07 & 0.13 & 0.07 & 0.1 & 0.1 & 0.2 \\
\hline & 0.2 & 0.06 & 0.07 & 0.07 & 0.13 & 0.07 & 0.1 & 0.1 & 0.2 \\
\hline & 0.2 & 0.06 & 0.07 & 0.07 & 0.13 & 0.07 & 0.1 & 0.1 & 0.2 \\
\hline & 0.2 & 0.06 & 0.07 & 0.07 & 0.13 & 0.07 & 0.1 & 0.1 & 0.2 \\
\hline & 0.2 & 0.06 & 0.07 & 0.07 & 0.13 & 0.07 & 0.1 & 0.1 & 0.2 \\
\hline & 0.2 & 0.06 & 0.07 & 0.07 & 0.13 & 0.07 & 0.1 & 0.1 & 0.2 \\
\hline & 0.2 & 0.06 & 0.07 & 0.07 & 0.13 & 0.07 & 0.1 & 0.1 & 0.2 \\
\hline
\end{tabular}




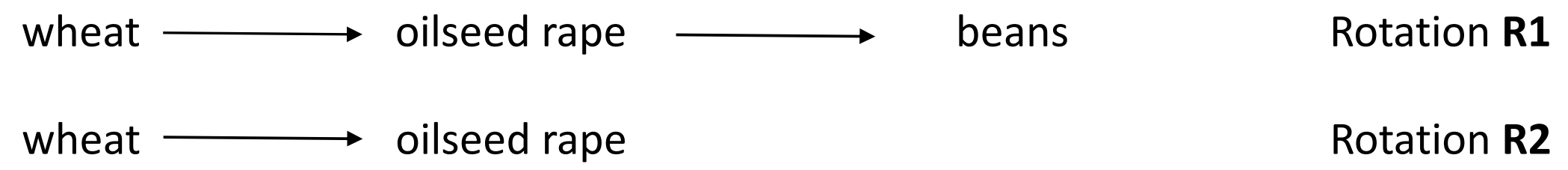

c. Transitions between rotations $R 1 \& R 2$

\begin{tabular}{|c|c|c|c|}
\hline \multirow{4}{*}{$\begin{array}{c}\text { Previous } \\
\text { year }\end{array}$} & & \multicolumn{3}{c|}{ Current year } \\
\cline { 2 - 4 } & Rotation R1 & Rotation R1 & Rotation R2 \\
\cline { 2 - 4 } & Rotation R2 & $r$ & $1-r$ \\
\hline
\end{tabular}

Transitions between rotations can themselves be represented as a single transition matrix 


\section{Temporal hetergeneity: Blocks of Fields}

Blocks of Fields: are fields managed by 1 farmer, following the same crop succession and starting with the same crop.

\begin{tabular}{|c|c|c|c|c|c|c|c|c|}
\hline \multirow{2}{*}{ Farmer } & \multirow{2}{*}{ FieldID } & \multirow{2}{*}{ Rotation } & \multicolumn{3}{|c|}{ Years in rotations } & \multicolumn{2}{|c|}{ Start Year } & \multirow{4}{*}{$\begin{aligned} & \text { Block of } \\
\rightarrow & \text { fields }\end{aligned}$} \\
\hline & & & 1 & 2 & 3 & 1 & \begin{tabular}{l|l}
2 & 3
\end{tabular} & \\
\hline \multirow[t]{3}{*}{4} & 40 & 3 & $\overline{\mathrm{W}}$ & $\overline{W D}$ & $\overline{\text { OSR }}$ & 1 & & \\
\hline & 52 & 3 & W & $\mathrm{Wb}$ & OSR & 1 & \multirow[b]{2}{*}{1} & \\
\hline & 38 & 3 & $\overline{\text { OSR }}$ & $\mathrm{W}$ & $\mathrm{Wb}$ & & & \\
\hline \multirow[t]{5}{*}{7} & 24 & 3 & W & $\mathrm{Wb}$ & $\overline{\text { OSR }}$ & 1 & \multirow{4}{*}{$\begin{array}{l}1 \\
1\end{array}$} & \\
\hline & 35 & 3 & W & $\mathrm{Wb}$ & OSR & 1 & & \\
\hline & 43 & 3 & $\mathrm{~Wb}$ & OSR & W & & & \\
\hline & 47 & 3 & $\mathrm{~Wb}$ & OSR & W & & & \\
\hline & 65 & 3 & OSR & W & Wb & & 1 & \\
\hline \multirow[t]{10}{*}{$\overline{9}$} & 7 & 3 & W & $\overline{W b}$ & OSR & 1 & \multirow{6}{*}{$\begin{array}{l}1 \\
1 \\
1 \\
1\end{array}$} & \\
\hline & 21 & 3 & W & $\mathrm{Wb}$ & OSR & 1 & & \\
\hline & 16 & 3 & $\mathrm{~Wb}$ & OSR & W & & & \\
\hline & 18 & 3 & Wb & OSR & W & & & \\
\hline & 22 & 3 & Wb & OSR & W & & & \\
\hline & 23 & 3 & Wb & OSR & w & & & \\
\hline & 26 & 3 & OSR & W & $\mathrm{Wb}$ & & 1 & Oil cond rano \\
\hline & 27 & 3 & OSR & w & $\mathrm{Wb}$ & & 1 & Ull seed rape \\
\hline & 28 & 3 & OSR & w & $\mathrm{Wb}$ & & 1 & Winter barley \\
\hline & 34 & 3 & OSR & W & Wb & & 1 & Wheat \\
\hline
\end{tabular}


Table 1

\begin{tabular}{|c|c|c|c|c|c|c|c|c|c|}
\hline \multirow[t]{2}{*}{ Field number } & \multicolumn{3}{|c|}{ Observed } & \multicolumn{3}{|l|}{ E1 } & \multicolumn{3}{|l|}{ E2 } \\
\hline & 1995 & 1996 & 1997 & 1995 & 1996 & 1997 & 1995 & 1996 & 1997 \\
\hline 7 & W & $w B$ & OSR & wB & OSR & W & W & $w B$ & OSR \\
\hline 16 & $\mathrm{wB}$ & OSR & W & $w B$ & OSR & W & W & $w B$ & OSR \\
\hline 18 & $w B$ & OSR & W & $w B$ & OSR & W & wB & OSR & W \\
\hline 21 & W & $w B$ & OSR & $w B$ & OSR & W & W & $w B$ & OSR \\
\hline 22 & wB & OSR & W & wB & OSR & W & $w B$ & OSR & W \\
\hline 23 & $w B$ & OSR & $\mathrm{W}$ & $w B$ & OSR & W & $w B$ & OSR & W \\
\hline 26 & OSR & W & $w B$ & $w B$ & OSR & W & OSR & W & $w B$ \\
\hline 27 & OSR & W & $w B$ & $w B$ & OSR & W & OSR & W & $w B$ \\
\hline 28 & OSR & W & $w B$ & $w B$ & OSR & W & OSR & W & $w B$ \\
\hline 34 & OSR & W & wB & OSR & W & $w B$ & OSR & W & $w B$ \\
\hline
\end{tabular}

Observed crop sequences for the 10 out of 13 fields in which grower 9 adopted the 3 -year rotation: oilseed rape (OSR), wheat (denoted W), winter barley (wB), over the period 1995-1997. Also shown are two imaginary possible reallocations of the starting crop of the rotation to yield different extremes of temporal heterogeneity. In E1 temporal heterogeneity is deliberately made almost maximal; in E2 it is made minimal. 


\section{Spatio-temporal analysis : blocks of fields}

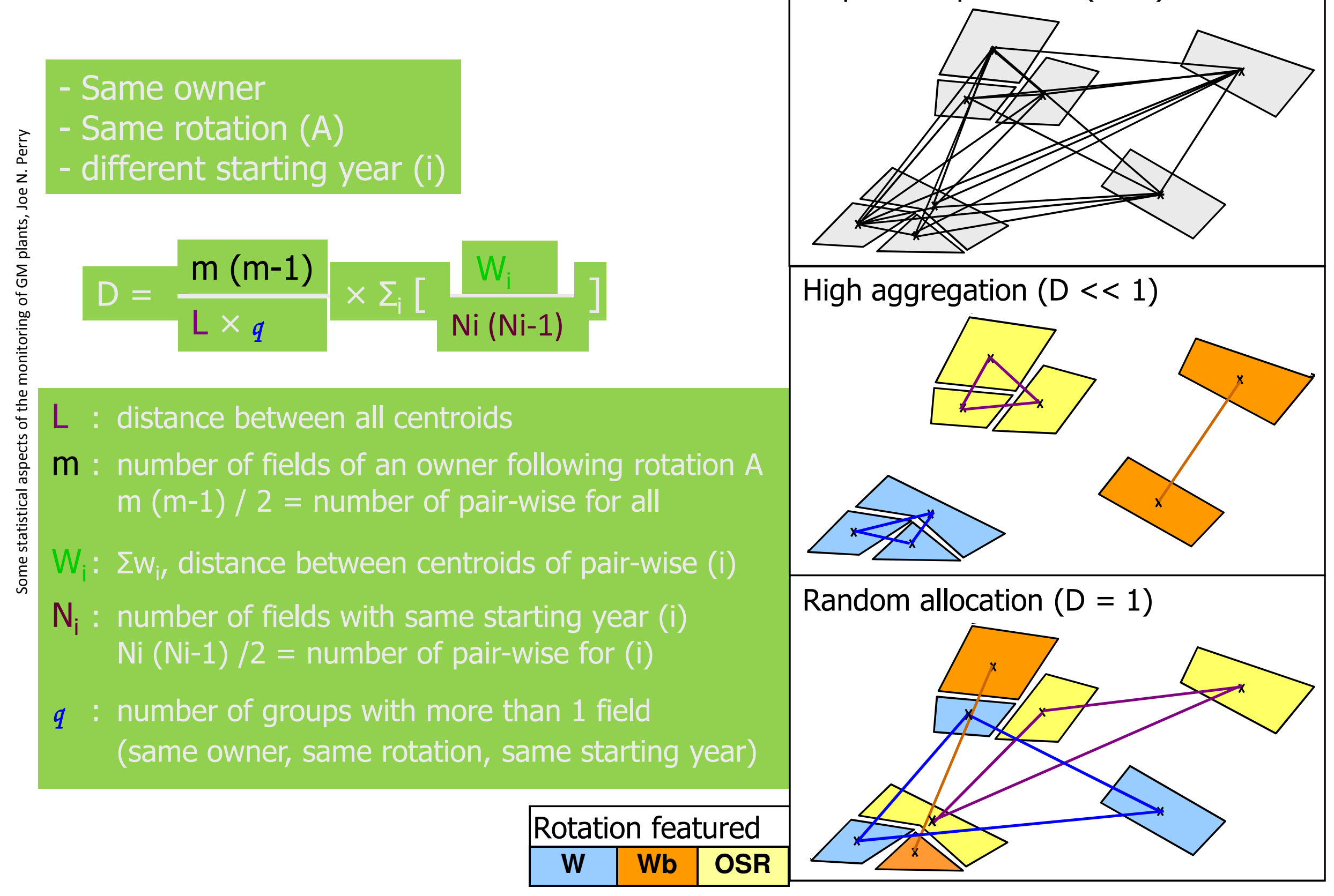

All possible pair-wise (for $\mathrm{L}$ )

High aggregation $(D<<1)$

Random allocation $(D=1)$ 

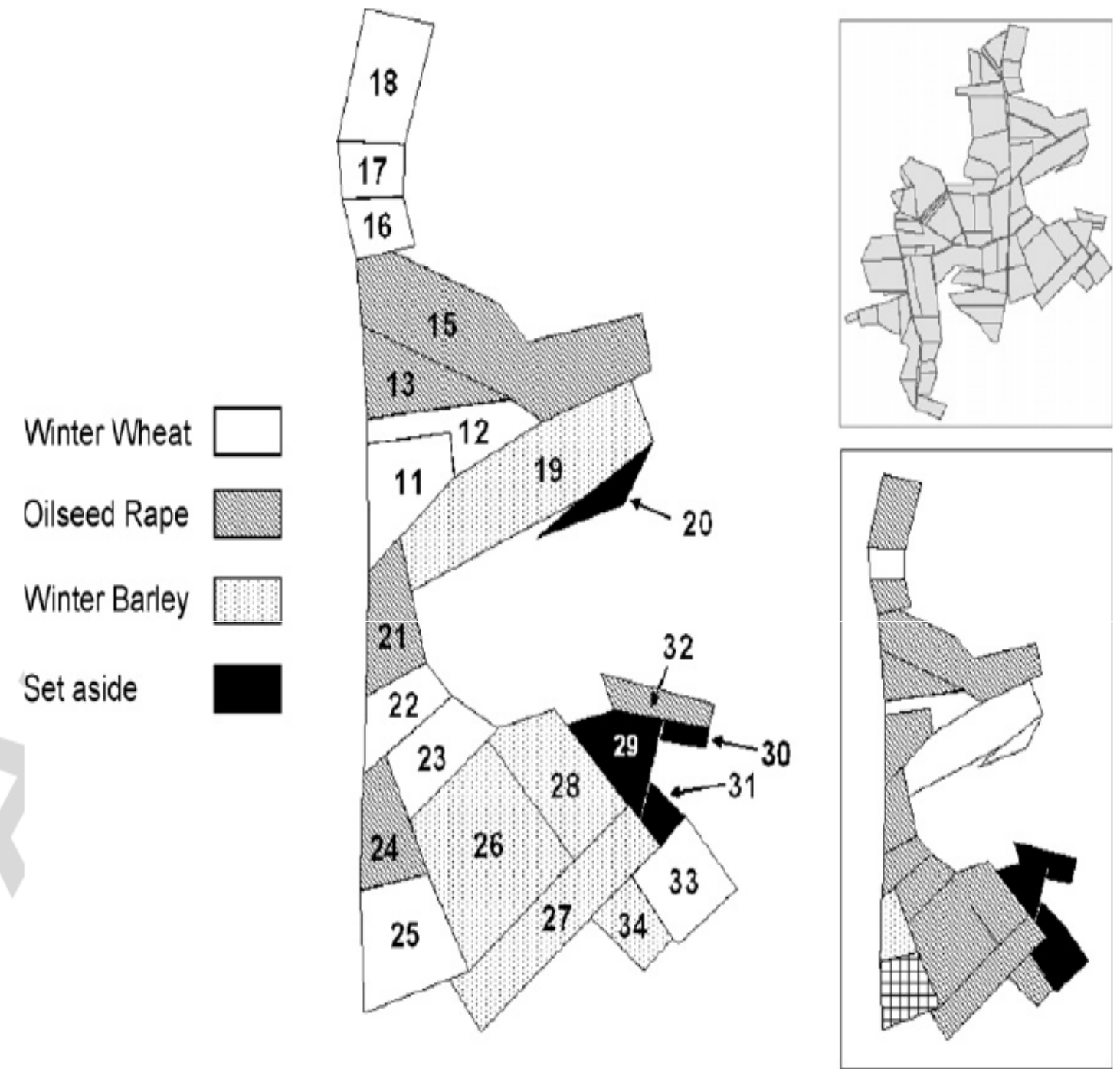

Fig. 1. Burgundy study landscape (France). A subset comprising the north and east of the Burgundy study landscape in 1997, showing the observed allocation of four crop types: wheat, barley, oilseed rape and set aside, to 23 fields, by five growers. Each field is shown with its reference number. Inset at top right shows the full landscape, comprising 72 fields and 10 growers. Inset at bottom right distinguishes different growers. 

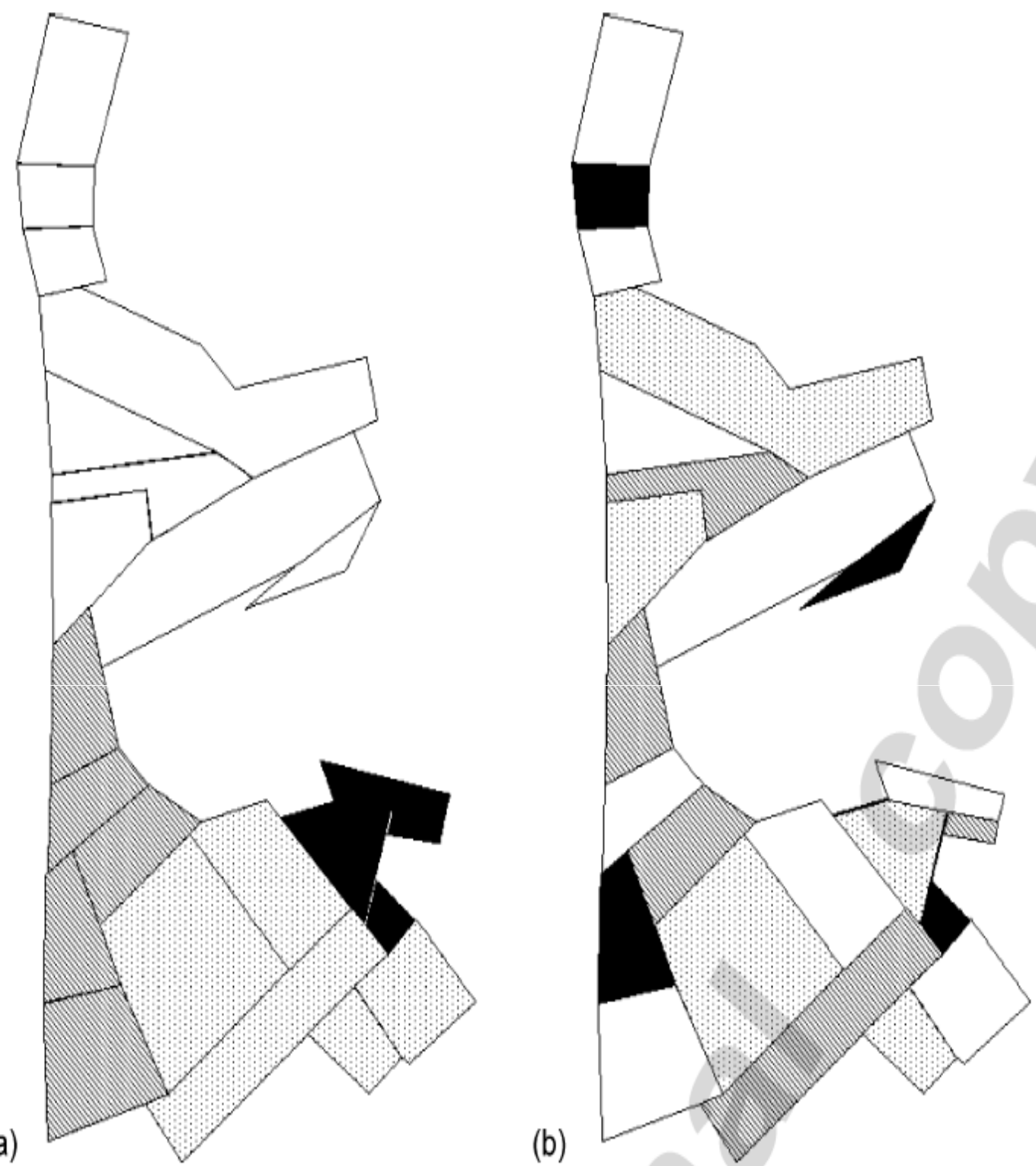

Fig. 2. Imaginary extreme spatial patterns for Burgundy data. Two examples of possible reallocations of the crop types in Fig. 1, to yield different extremes of spatial pattern. (a) In the nine wheat fields, five barley, five oilseed rape and four set aside crops are reallocated to achieve a large degree of aggregation of crops, where identical types cluster together. (b) In the crop types are reallocated to demonstrate homogeneity, so that no crop type is a nearest neighbour of itself. Shading for crop types as in Fig. 1. 
Coexistence scenarios need for separation distance between GM and non-GM farmers

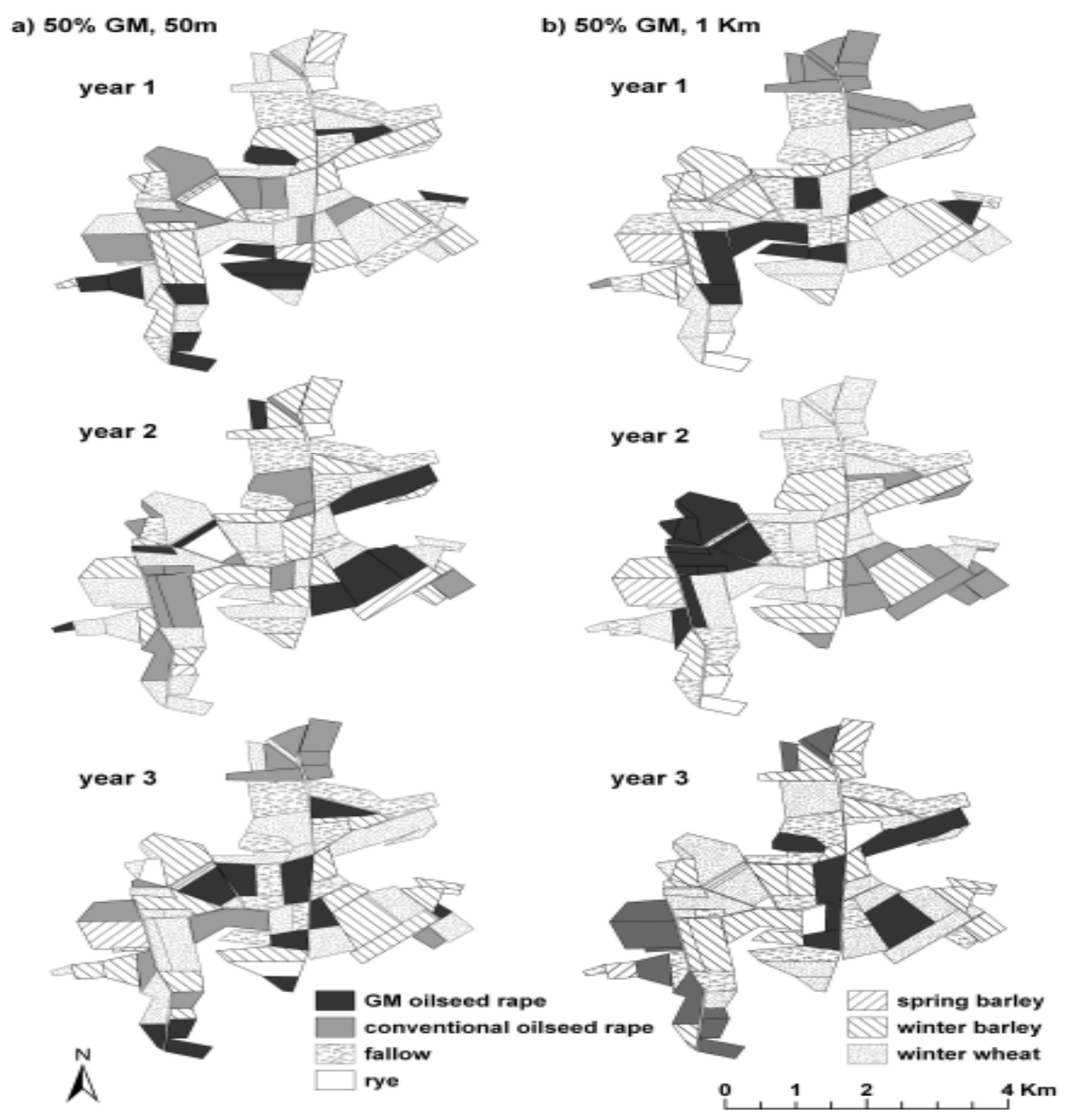




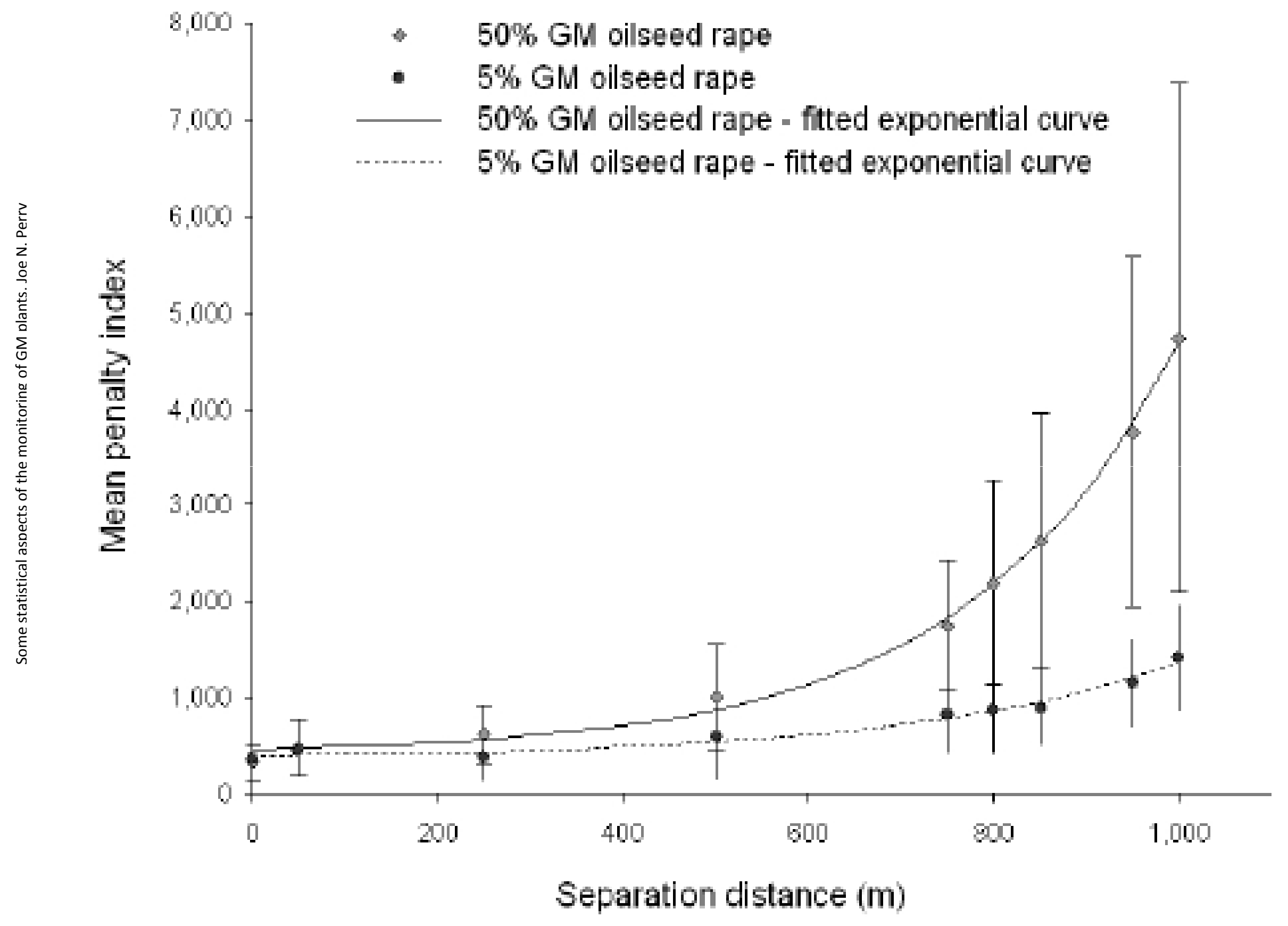




\section{Temporal pattern - Temporal conditions User interface}

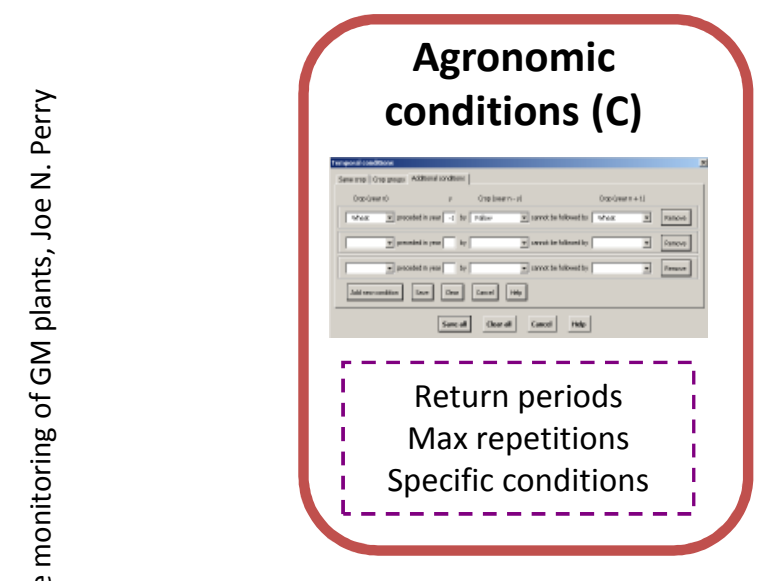

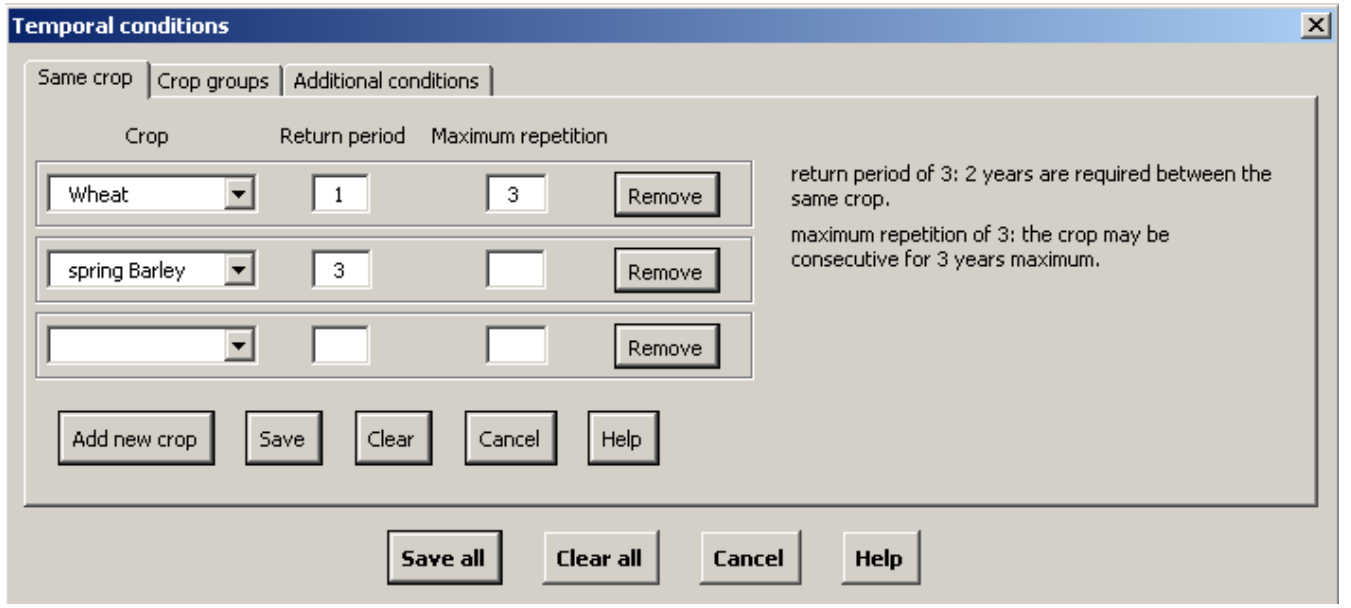

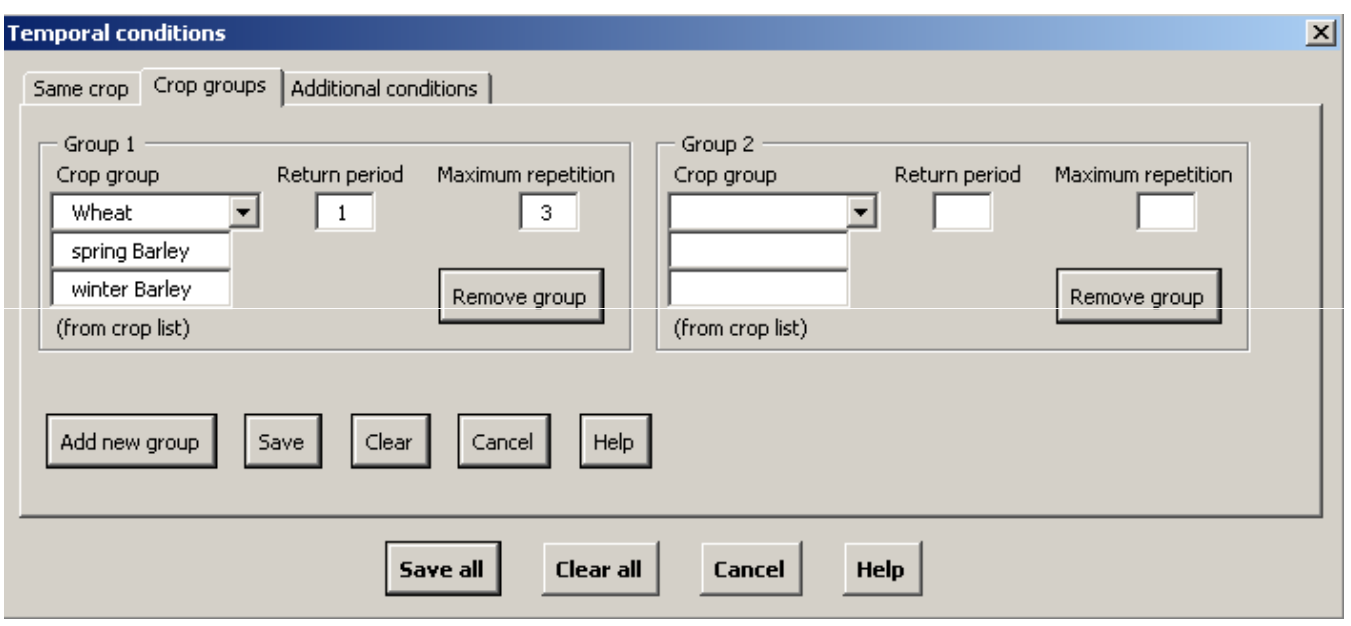

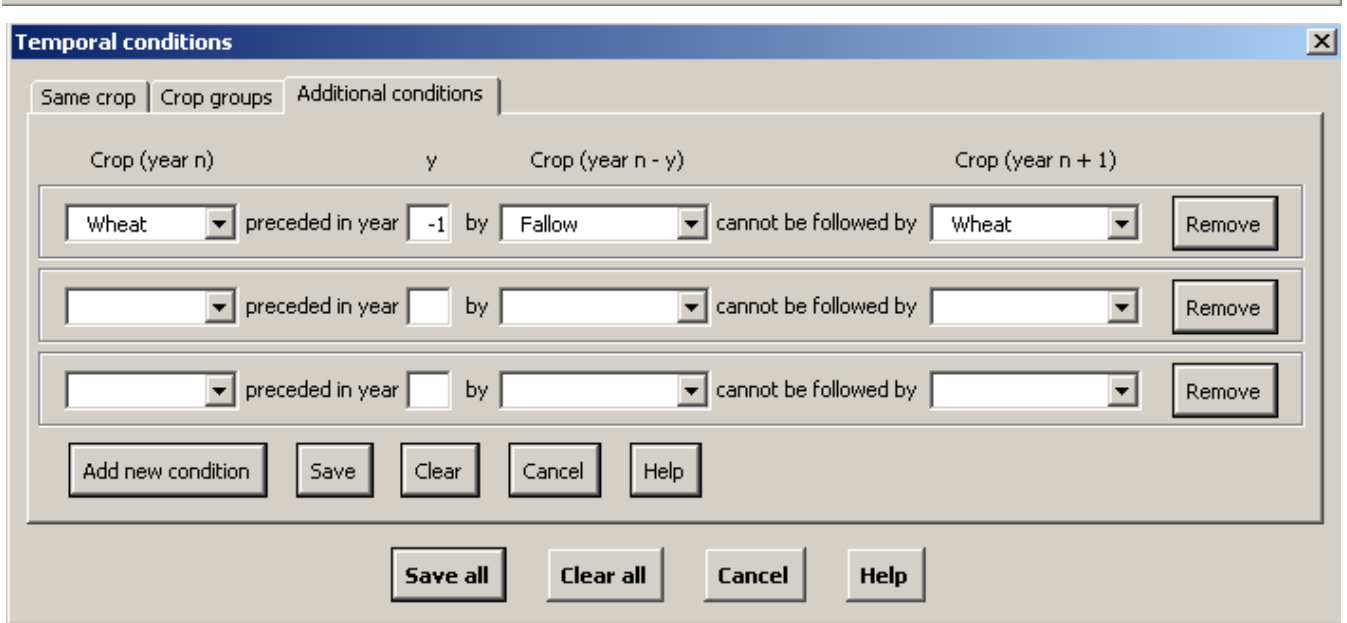




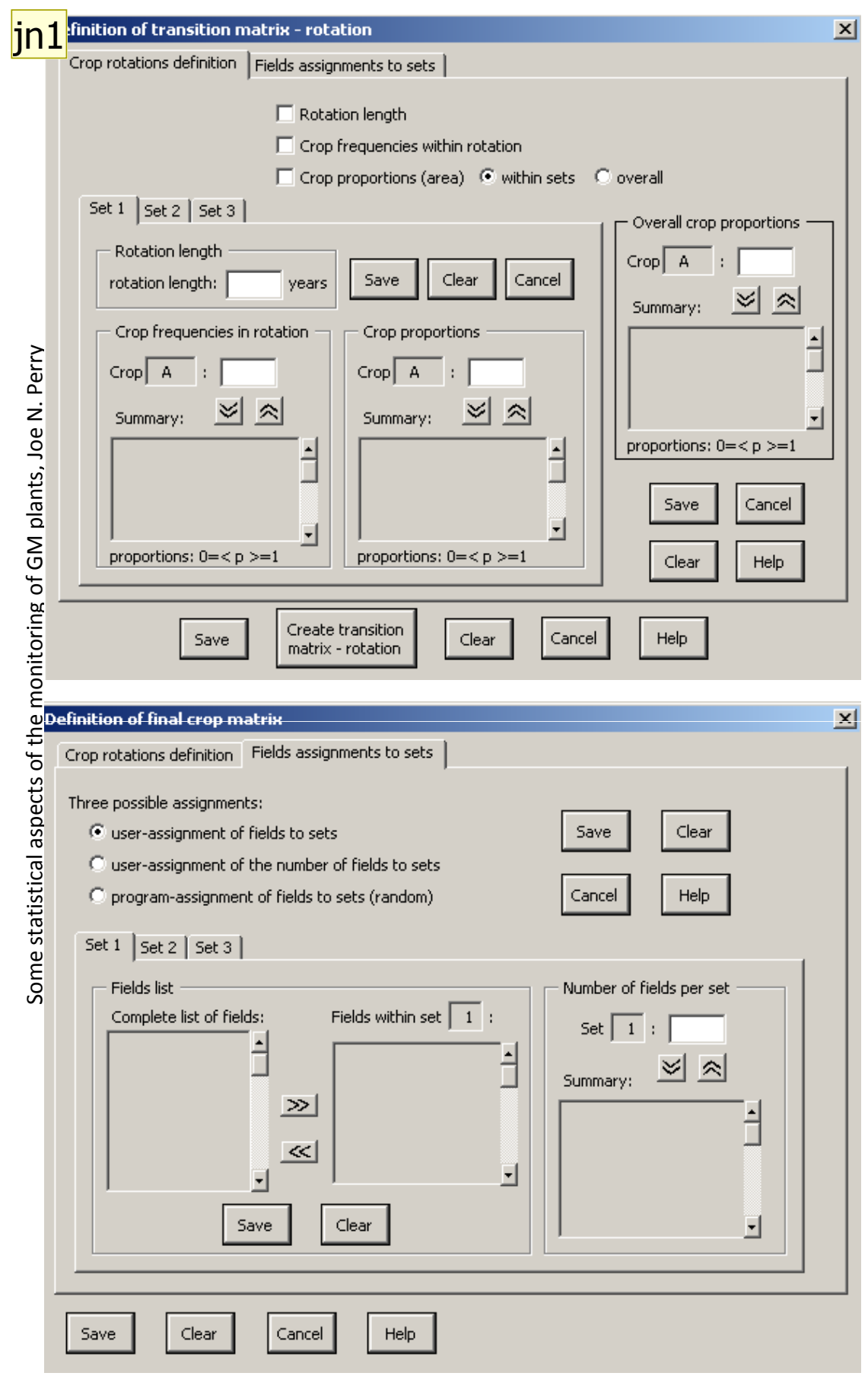

\section{Temporal pattern - \\ Definition of final temporal matrix User interface}
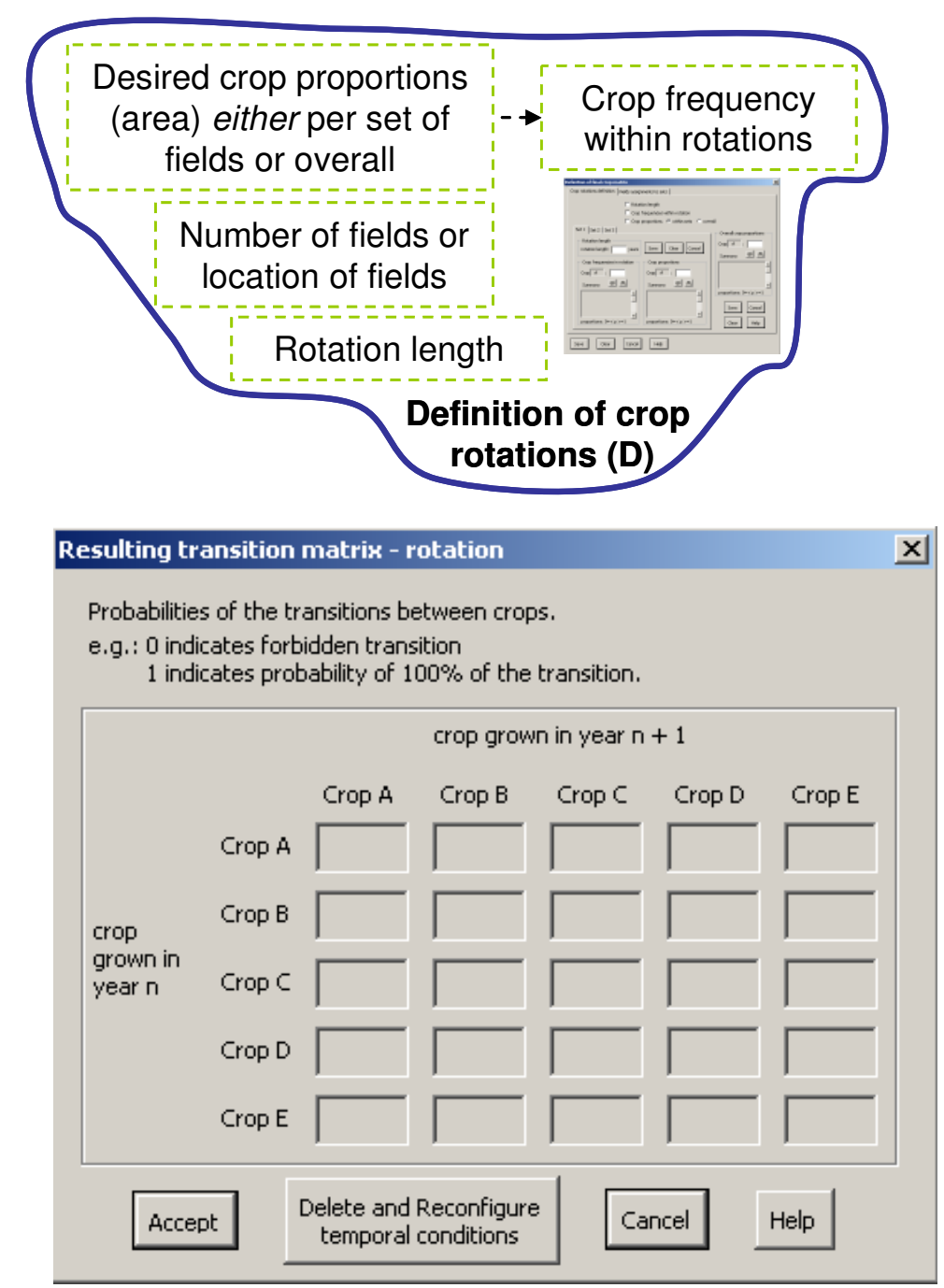
jn1 I am now not sure that this transition matrix of rotations (master transition matrix) is necessary. I think we agreed that jumping to a predetermined rotation would be too complex to implement, and unrealistic. If we want to incorporate the practice of jumping between rotations this can, in any case, be modelled through the user-defined transition matrix approach. Indeed, my current thinking is that perhaps it will not be necessary to incorporate this at the user-entry stage since it is not very realistic. If we, as researchers, wanted to study the effects of a stochastic change of rotations, we can do so by using the 'rotations_aand_transition_matrices.doc' document to calculate the appropriate transition matrix and then we can specify it directly. In that case, the user does not actually need the 'master transition matrix' or 'transition matrix between rotations' at all.

perry; 23.01.2006 


\section{Parcels within fields, fields within holdings,}

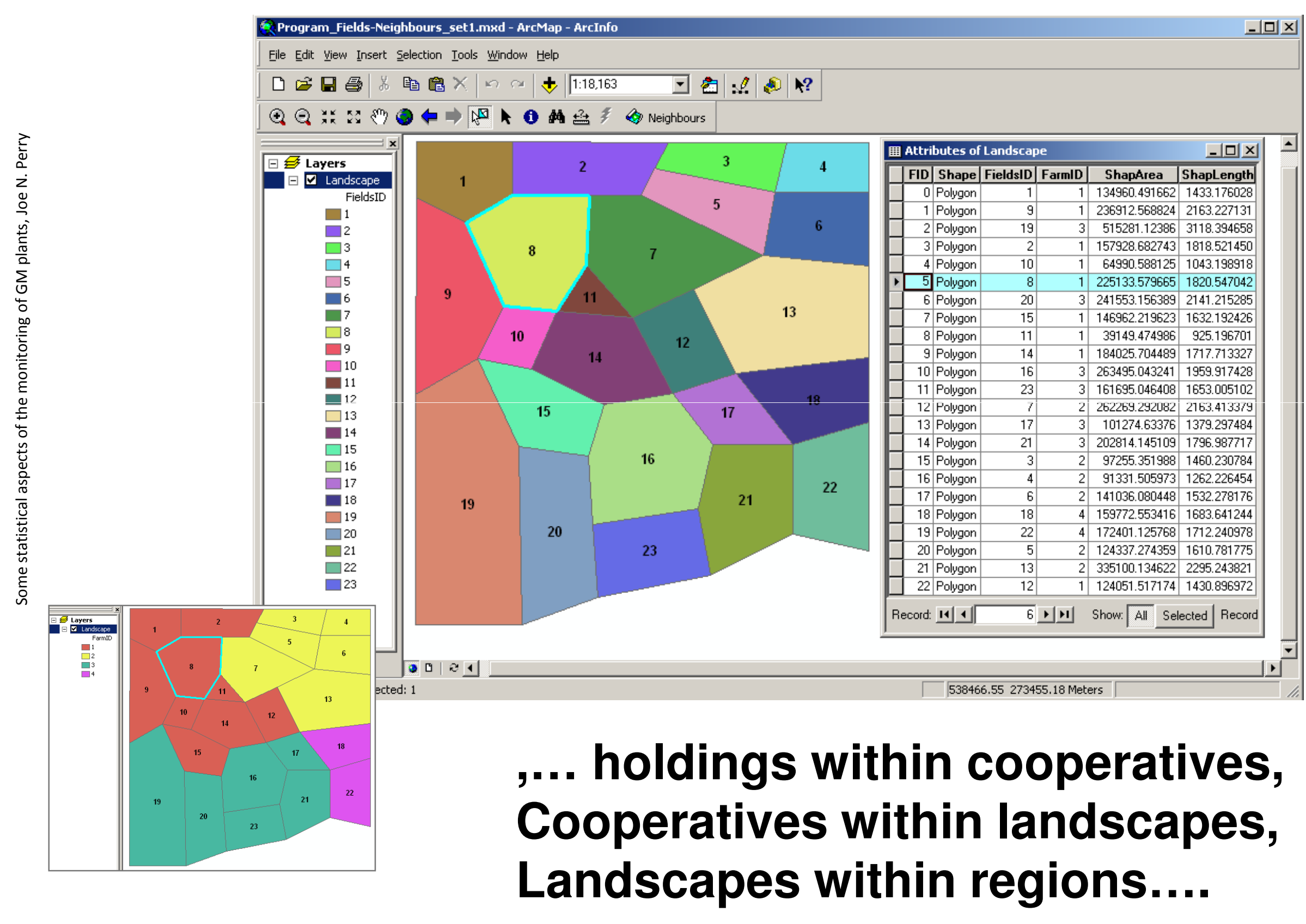


New measures and tests of temporal and spatial pattern of crops in agricultural landscapes

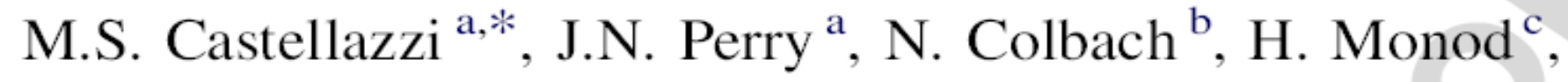
K. Adamczyk ${ }^{\mathrm{c}}$, V. Viaud ${ }^{\mathrm{c}}$, K.F. Conrad ${ }^{\mathrm{a}}$

\section{Agricultural Systems 97 (2008) 26-33}

A systematic representation of crop rotations

M.S. Castellazzi ${ }^{\text {a,* }}$, G.A. Wood ${ }^{\text {b }}$, P.J. Burgess ${ }^{\text {b }}$, J. Morris ${ }^{b}$, K.F. Conrad ${ }^{a}$, J.N. Perry ${ }^{a}$

Simulation scenarios of spatio-temporal arrangement of crops at the landscape scale M. S. Castellazzi a, b, J. Matthews ${ }^{\text {a, }}$ F. Angevin ${ }^{c}$, C. Sausse ${ }^{\text {d }}$, G.A. Wood P. J. Burgess ${ }^{e}$, I. Brown ${ }^{\text {b }}$, K. F. Conrad ${ }^{\text {a }}$, J. N. Perry ${ }^{\text {a }}$.

4

Availability: http://www.rothamsted.ac.uk/pie/LandSFACTS/ - free to use under the GNU Public licence, version 2. Subsequent versions:

http://www.macaulay.ac.uk/LandSFACTS/ 


\section{Decreases in abundance and occupancy of the garden tiger moth, Arctia caja, in the UK}

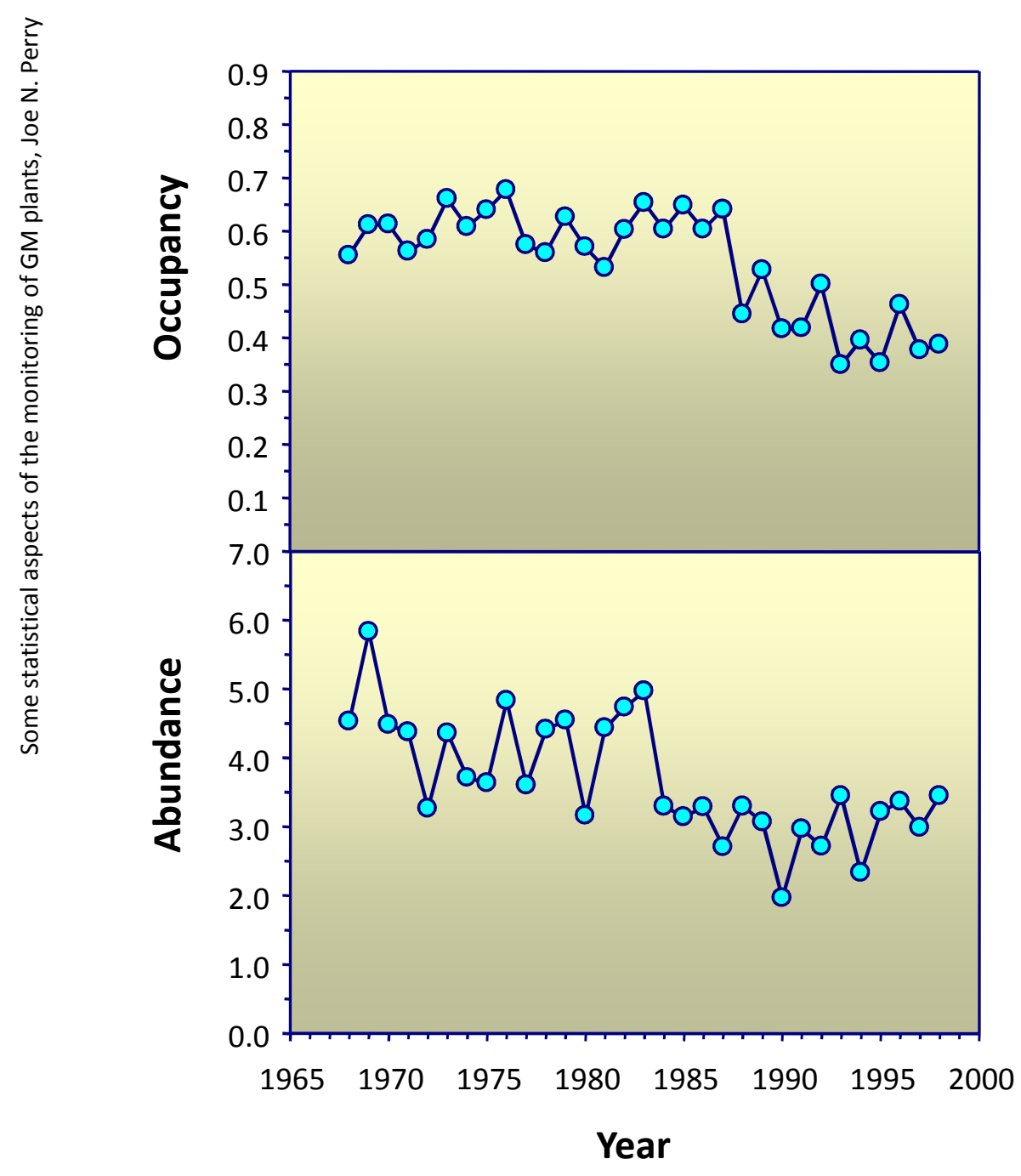

- The proportion of occupied sites has declined $\sim 30 \%$

- The abundance at occupied sites has also declined $\sim 30 \%$

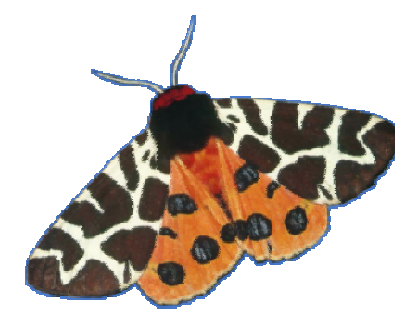

Year 


\section{Changes in where the moth is found}

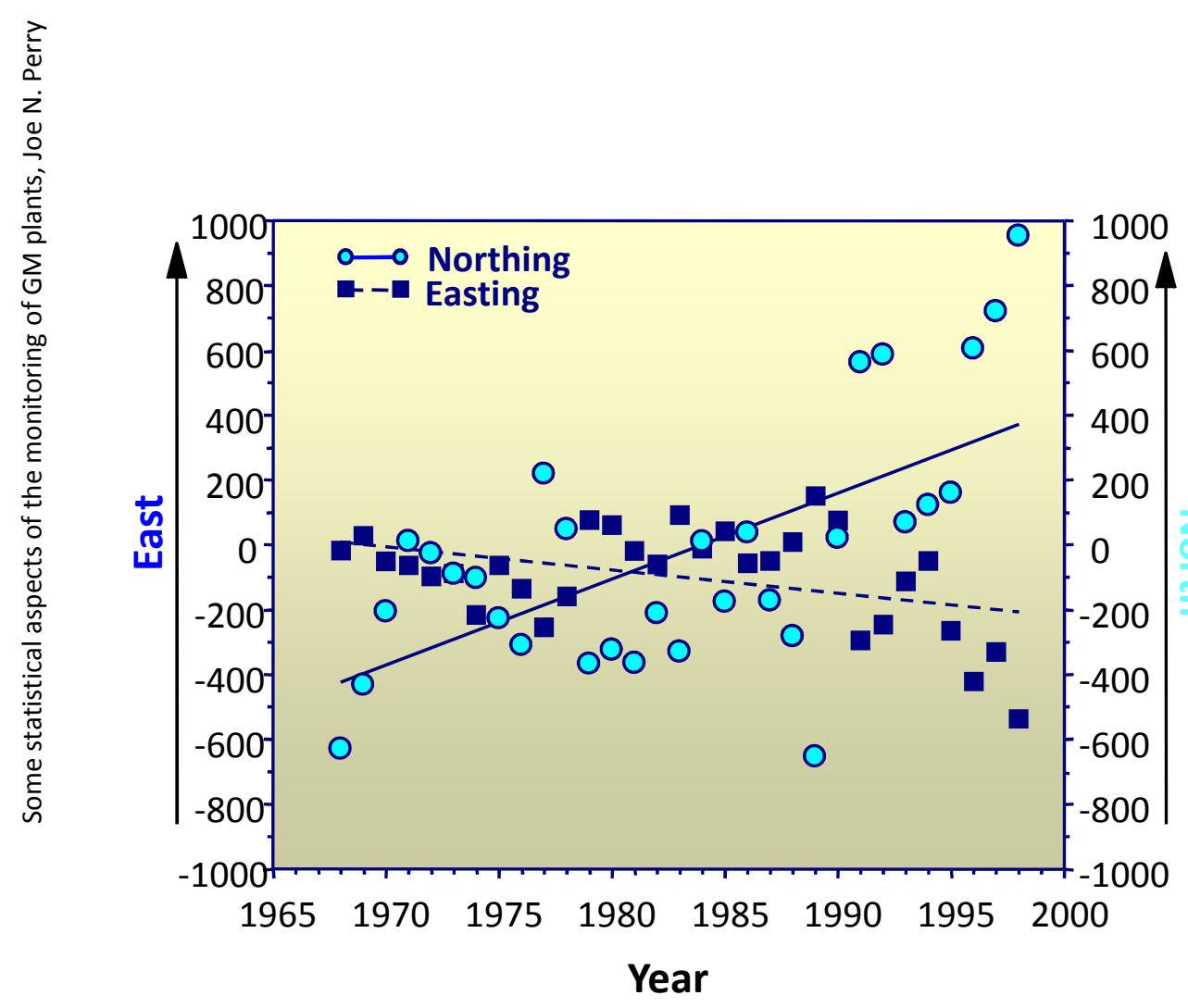

- Map co-ordinates of traps catching Arctia caja

- Centres of occupancy moved north and slightly west over time 


\section{ratches and gaps in aistribution}

- SADIE Identifies clusters of sampling points with similar counts

- Cluster of relatively large counts is a patch (red)

- Cluster of relatively small counts is a gap (blue)

- Areas where spatial pattern is weak (random distribution of counts) coloured white

- Patch and gap size not strongly affected by 'good' and 'bad' years

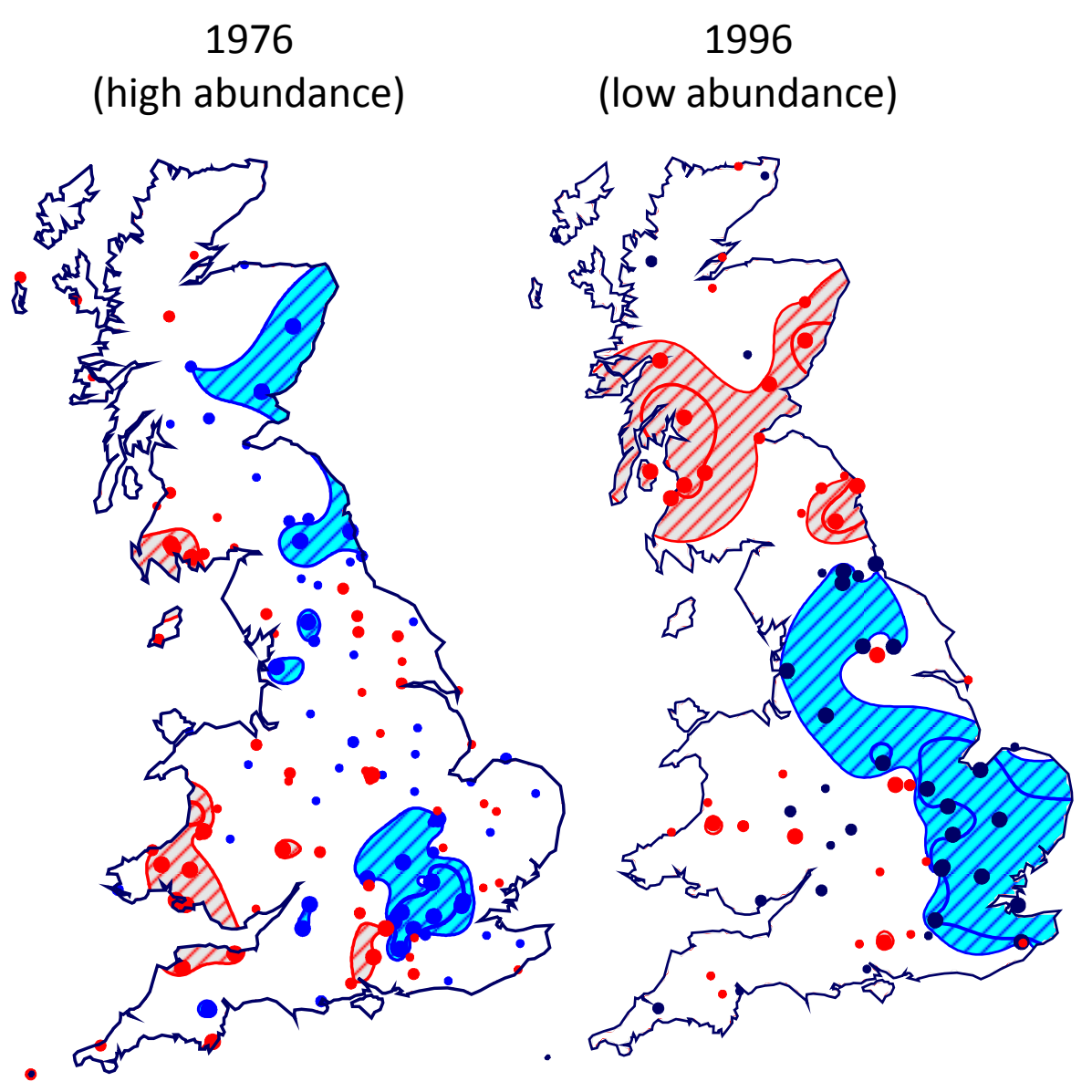

for up-to-date and free SADIE software visit: http://home.cogeco.ca/ sadiespatial/index.html

and also http://www.rothamsted.bbsrc.ac.uk/pie/sadie/SADIE home page 1.htm 


\section{Spatial pattern reversal over time}
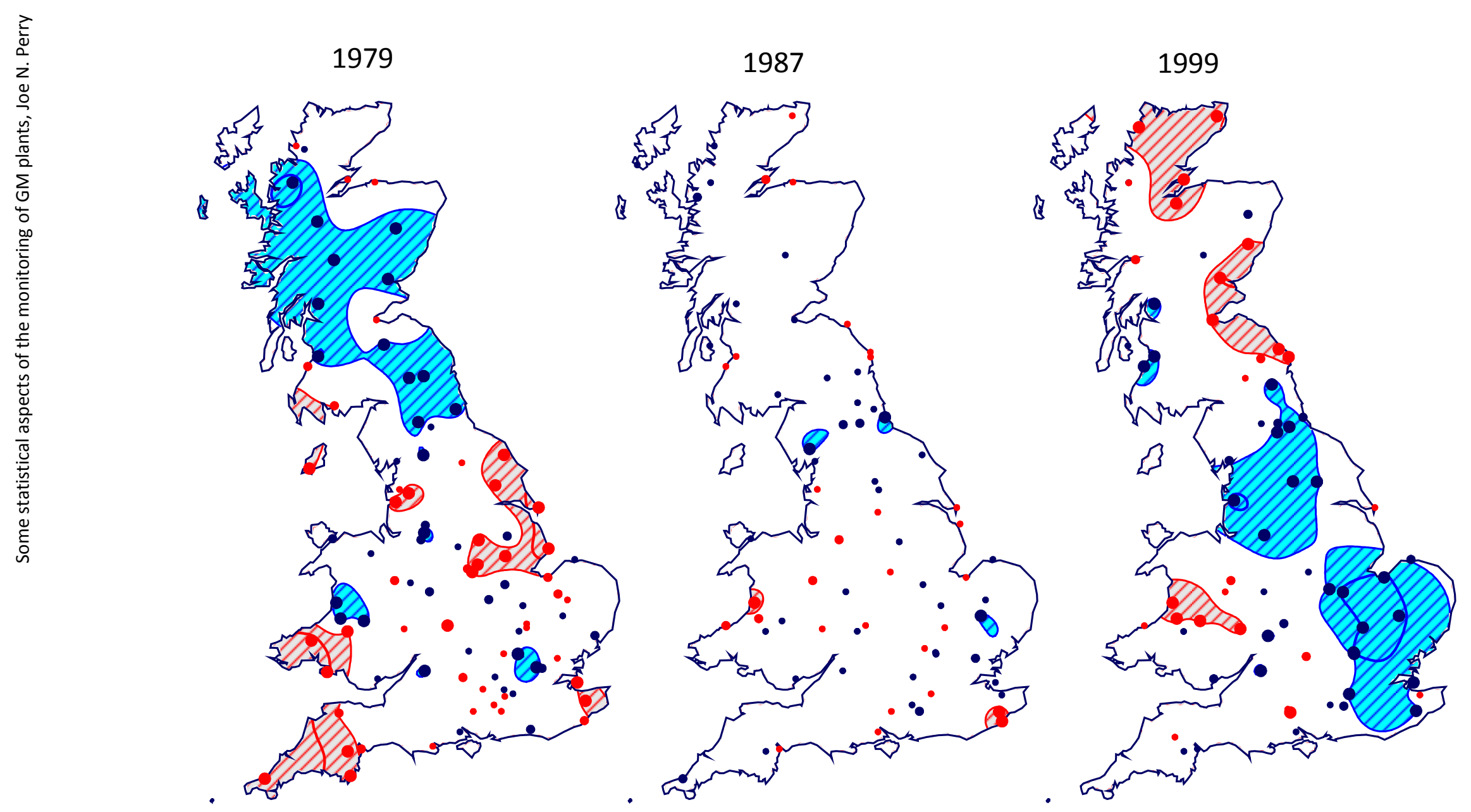


\section{Papers on Arctia caja and decline of monitored lepidoptera}

Conrad, K.F., Perry, J.N. \& Woiwod, I.P. (2001). An Abundance-Occupancy Time-lag During the Decline of an Arctiid Tiger Moth. Ecology Letters, 4, 300-303.

Conrad, K.F., Woiwod, I.P. \& Perry, J.N. (2002). Long-term decline in abundance and distribution of the garden tiger moth (Arctia caja) in Great Britain. Biological Conservation, 106, 329-337.

Conrad, K.F., Woiwod, I.P. \& Perry, J.N. (2003) East Atlantic teleconnection pattern and the decline of a common arctiid moth. Global Change Biology, 9, 125-130.

Conrad, K.F., Perry, J.N., Woiwod, I.P. \& Alexander, C.J. (2006) Large-scale temporal changes in spatial pattern during declines of abundance and occupancy in a common moth. Journal of Insect Conservation, 10, 53-64. DOI 10.1007/s10841-005-1618-2. 


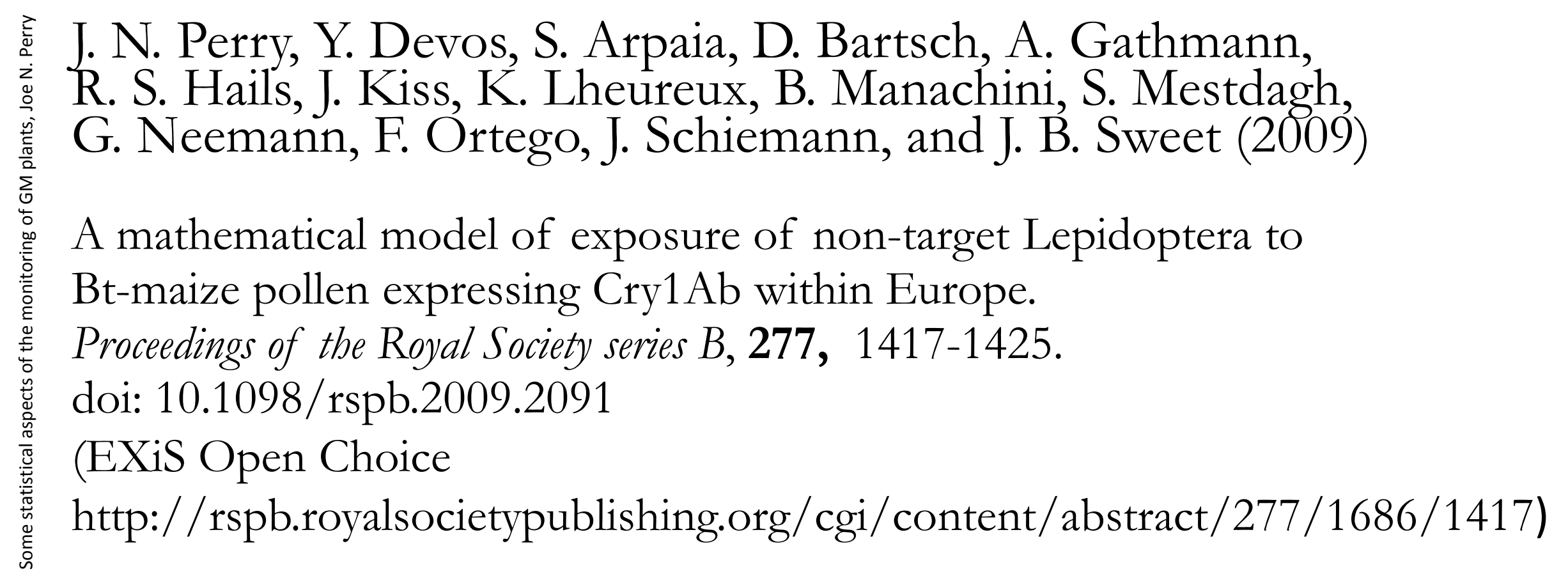




\section{... and three Lepidopteran species}

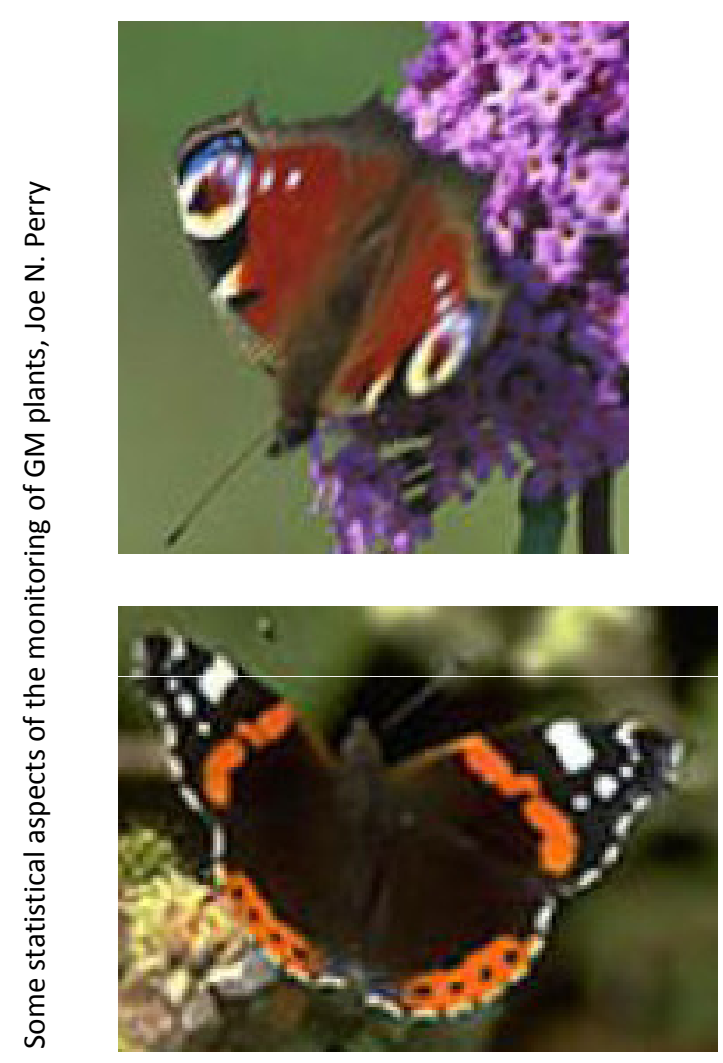

The Peacock butterfly:

Inachis io

with host plant Urtica dioica

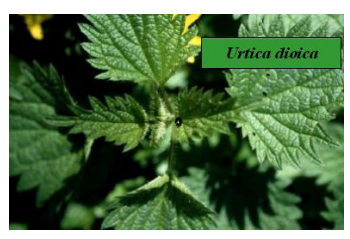

The Red Admiral butterfly:

Vanessa atalanta

with host plant Urtica dioica
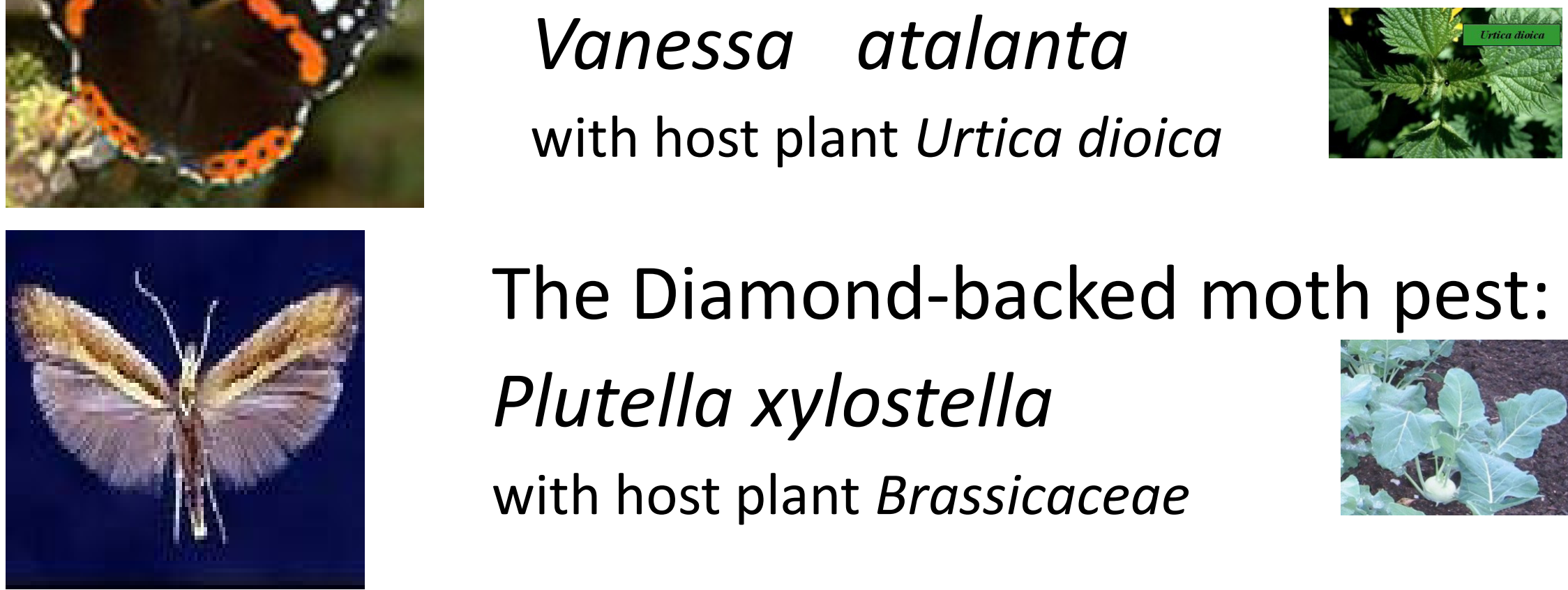

The Diamond-backed moth pest:

Plutella xylostella

with host plant Brassicaceae

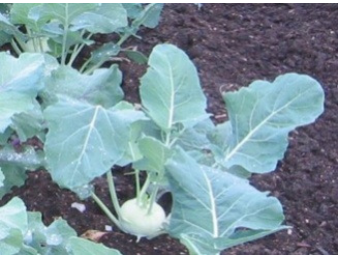




\begin{tabular}{|c|c|c|c|c|c|}
\hline $\begin{array}{c}\text { Parameter } \\
\text { (bold type and orange shading } \\
\text { indicates parameter reduces } \\
\text { worst-case exposure) }\end{array}$ & $\begin{array}{l}\text { Large } / \text { Small } \\
\text { scale }\end{array}$ & $\begin{array}{c}\text { Generic/Specific } \\
\text { to lepidopteran } \\
\text { species }\end{array}$ & $\begin{array}{l}\text { Generic/Specific } \\
\text { to host-plant }\end{array}$ & $\begin{array}{l}\text { Generic/Specific } \\
\text { to region }\end{array}$ & How derived \\
\hline $\begin{array}{c}z \\
\text { proportion crops in maize }\end{array}$ & Large & Generic & Generic & Specific & official statistics \\
\hline $\begin{array}{c}v \\
\text { Bt uptake rate }\end{array}$ & Large & Generic & Generic & Specific & $\begin{array}{l}\text { Spain: statistics; } \\
\text { elsewhere:: set as } \\
\text { worst-case }\end{array}$ \\
\hline $\begin{array}{c}y \\
\text { propn. host-plants in arable }\end{array}$ & Large & Generic & Specific & Specific & surveys/experts \\
\hline $\begin{array}{c}C \\
\text { size of maize fields }\end{array}$ & Small & Generic & Generic & Specific & official statistics \\
\hline $\begin{array}{c}D \\
\text { width of margin }\end{array}$ & Small & Generic & Generic & Specific & surveys/experts \\
\hline $\begin{array}{c}e \\
\text { density host-plant in crop }\end{array}$ & Small & Generic & Specific & Specific & surveys/experts \\
\hline $\begin{array}{c}f \\
\text { density host-plant in margin }\end{array}$ & Small & Generic & Specific & Specific & surveys/experts \\
\hline $\begin{array}{c}x \\
\text { physical effects }\end{array}$ & Small & Specific & Specific & Specific & experts \\
\hline $\begin{array}{c}a \\
\text { temporal coincidence }\end{array}$ & Large & Specific & Specific & Specific & experts \\
\hline $\begin{array}{c}g(E) \\
\text { worst-case mortality: margin }\end{array}$ & Small & Specific & Generic & Generic & calculated \\
\hline $\begin{array}{c}h \\
\text { worst-case mortality : crop }\end{array}$ & Small & Specific & Generic & Generic & calculated \\
\hline
\end{tabular}




\section{'Large-scale' parameters: $y, z, v$}

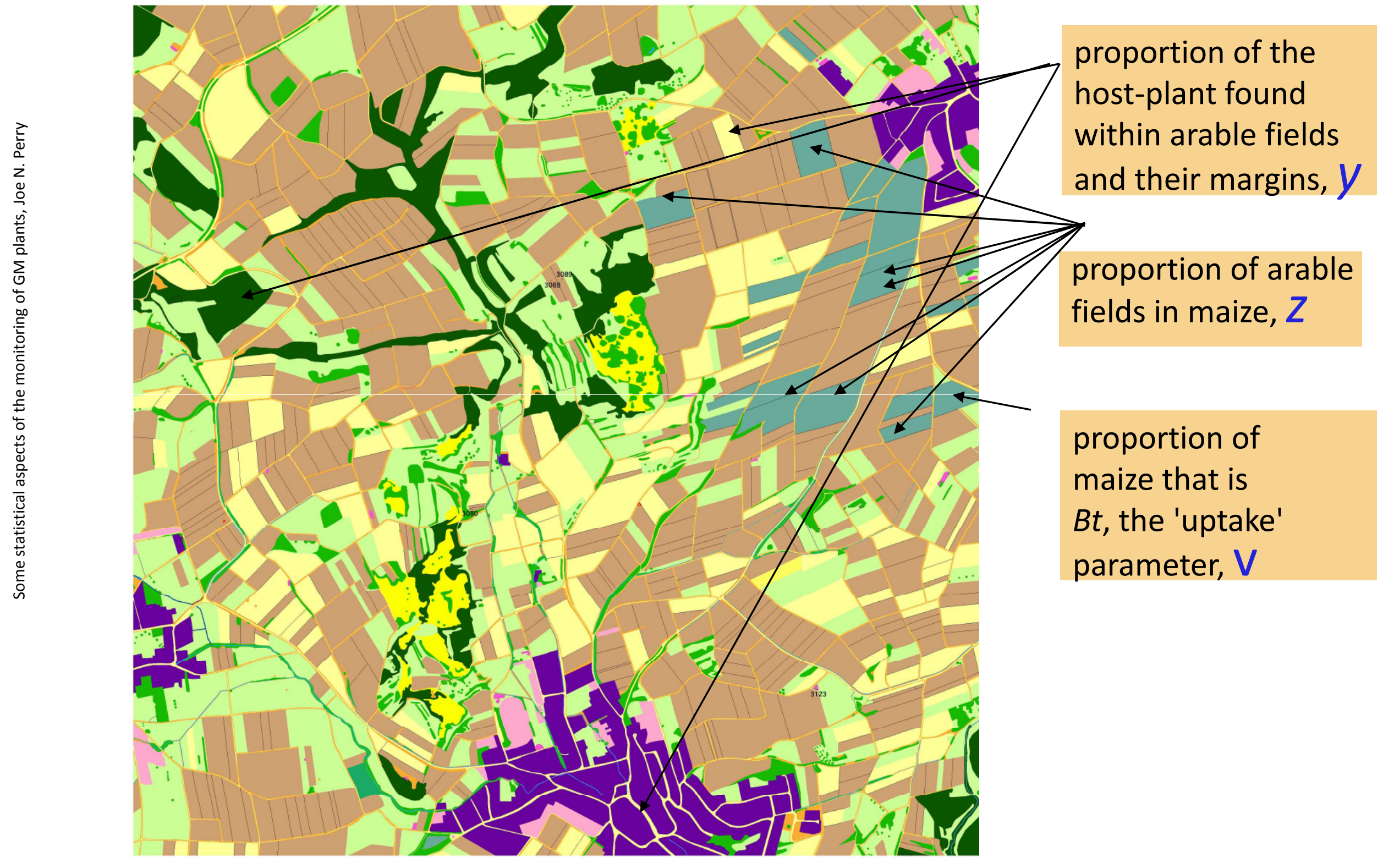




\section{'Small-scale' parameters: $C, D, e, f$}

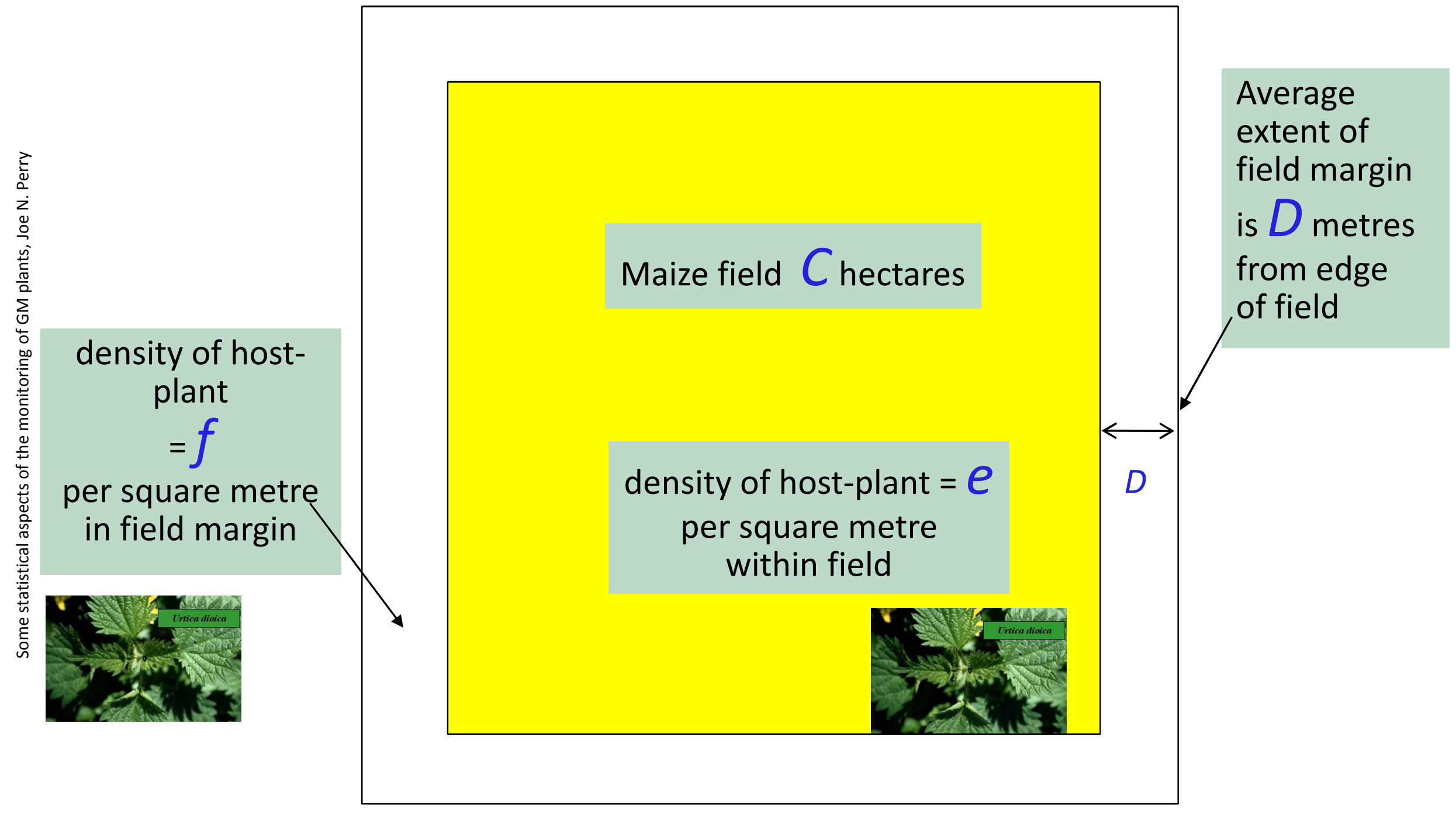

These parameters: $C, D, e, f$, do not reduce mortality.

They provide a means of weighting overall mortality between the 'within-crop' and 'within-margin' components 


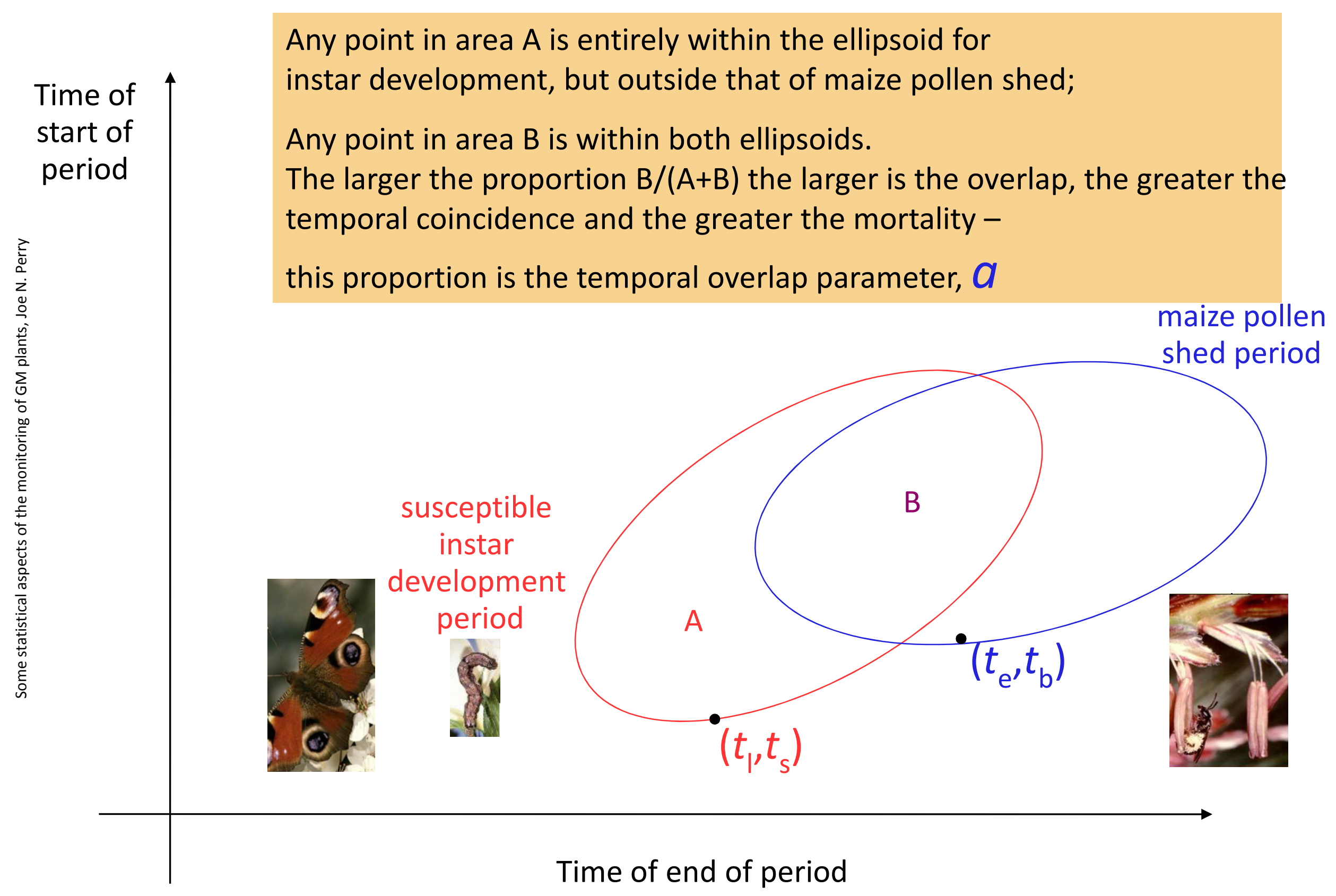



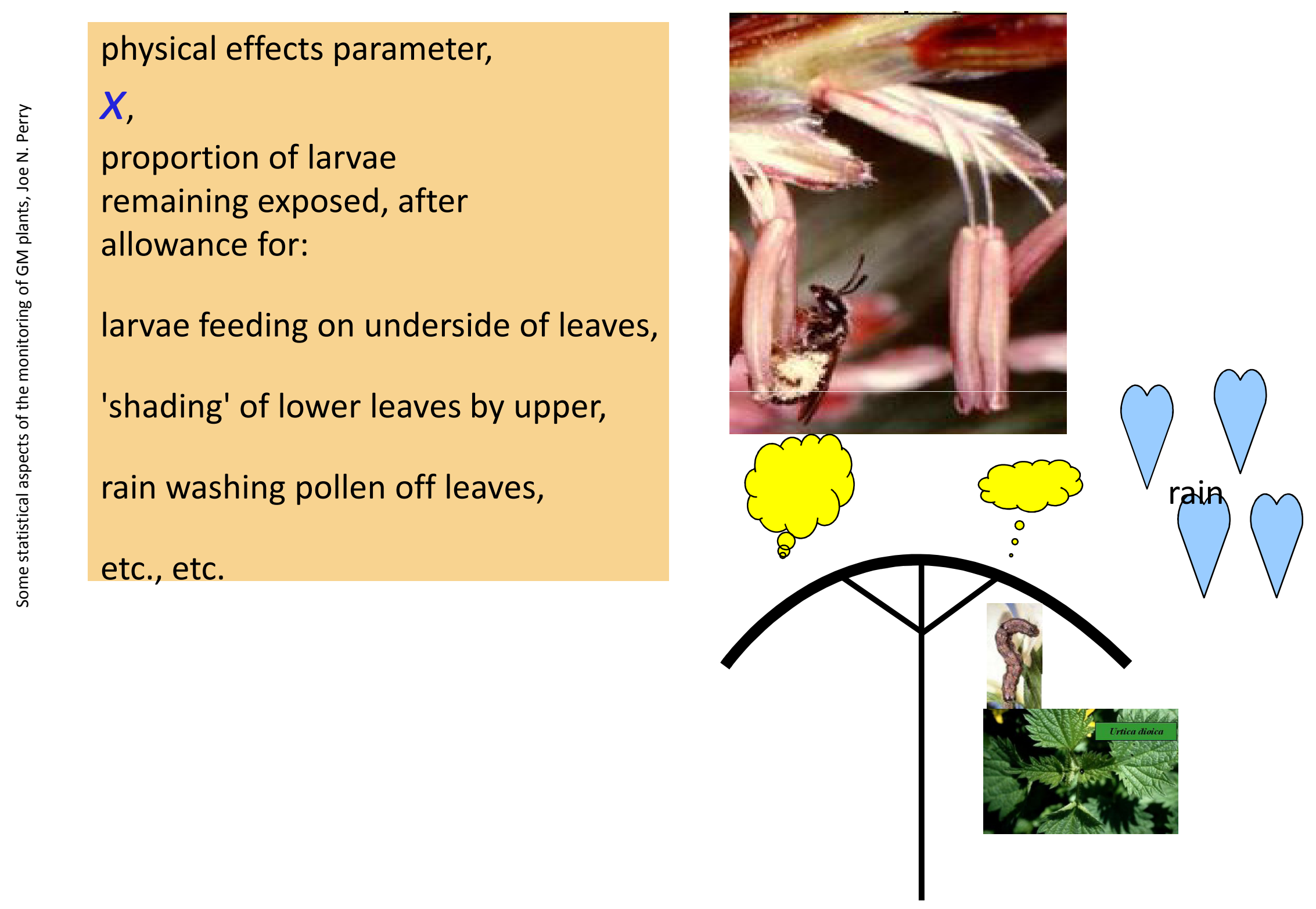
Mortality due to pollen in the field

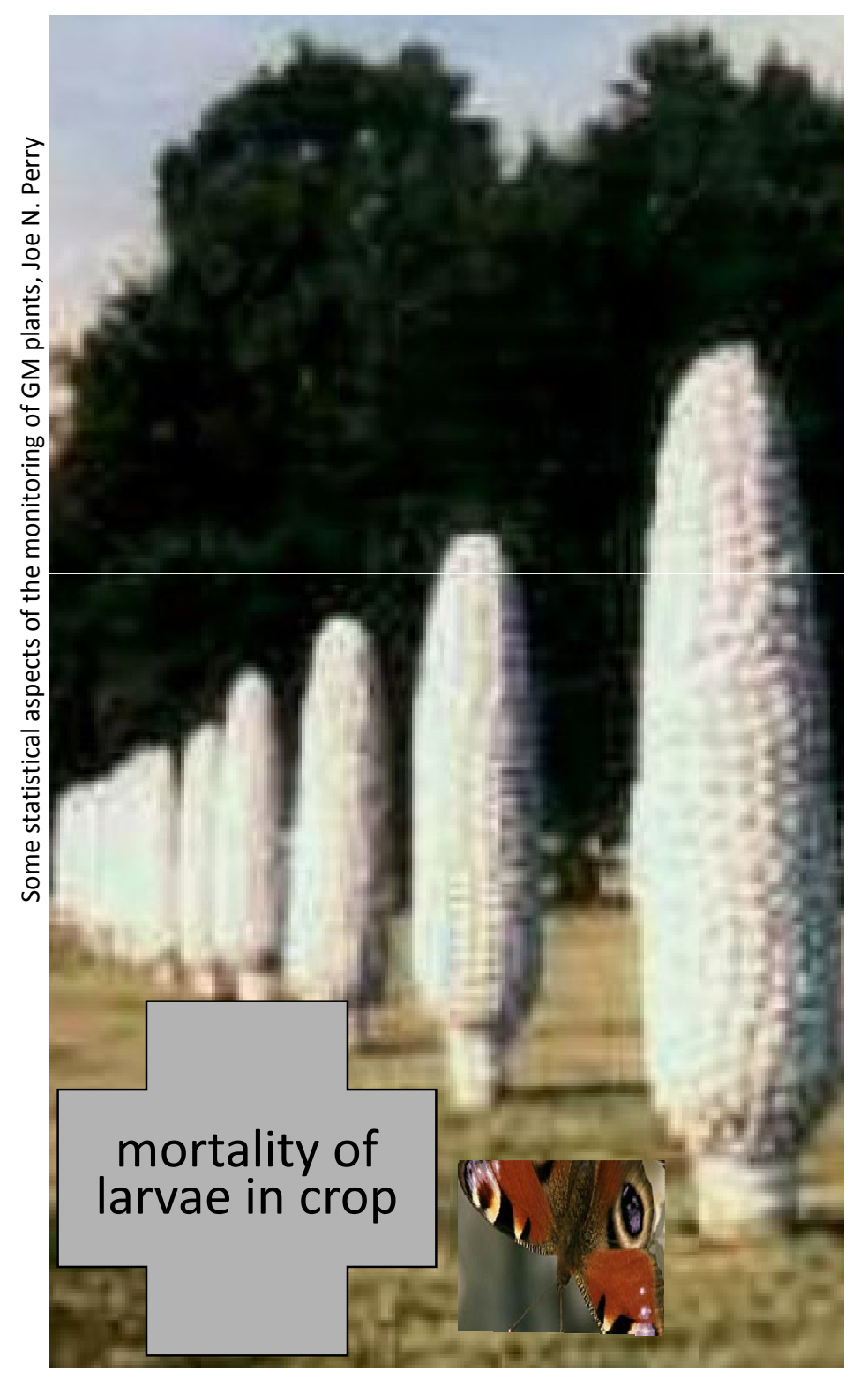

proportion of larvae suffering mortality in the field worst-case scenario, $h$

Mortality due to pollen in the margin

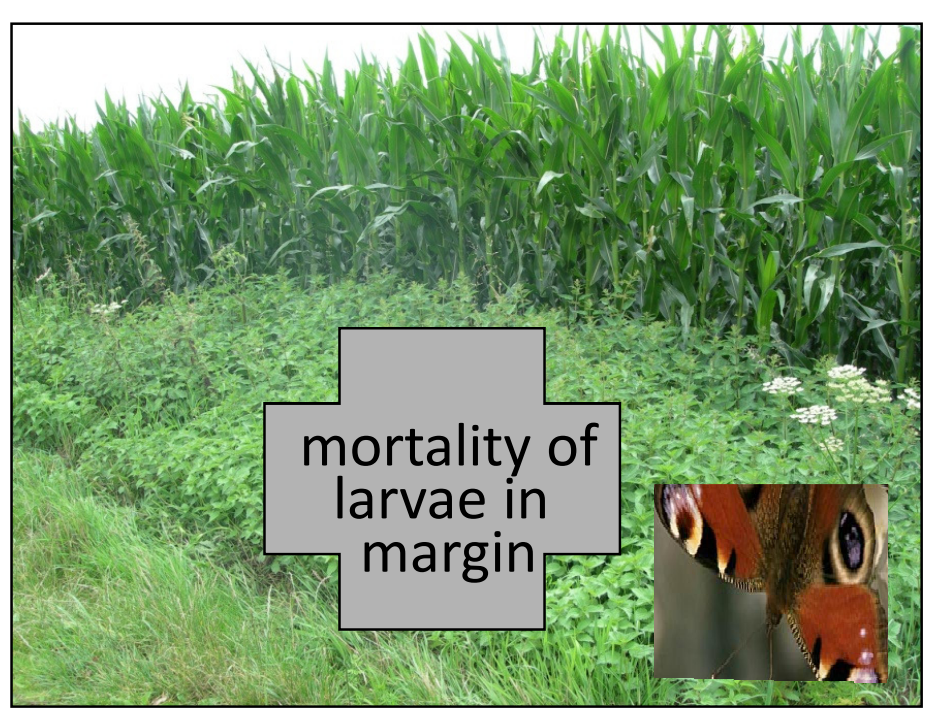

proportion of larvae suffering mortality at distance $E$ from edge of field worst-case scenario, $g(E)$ 


\section{Overview of new approach - biological}
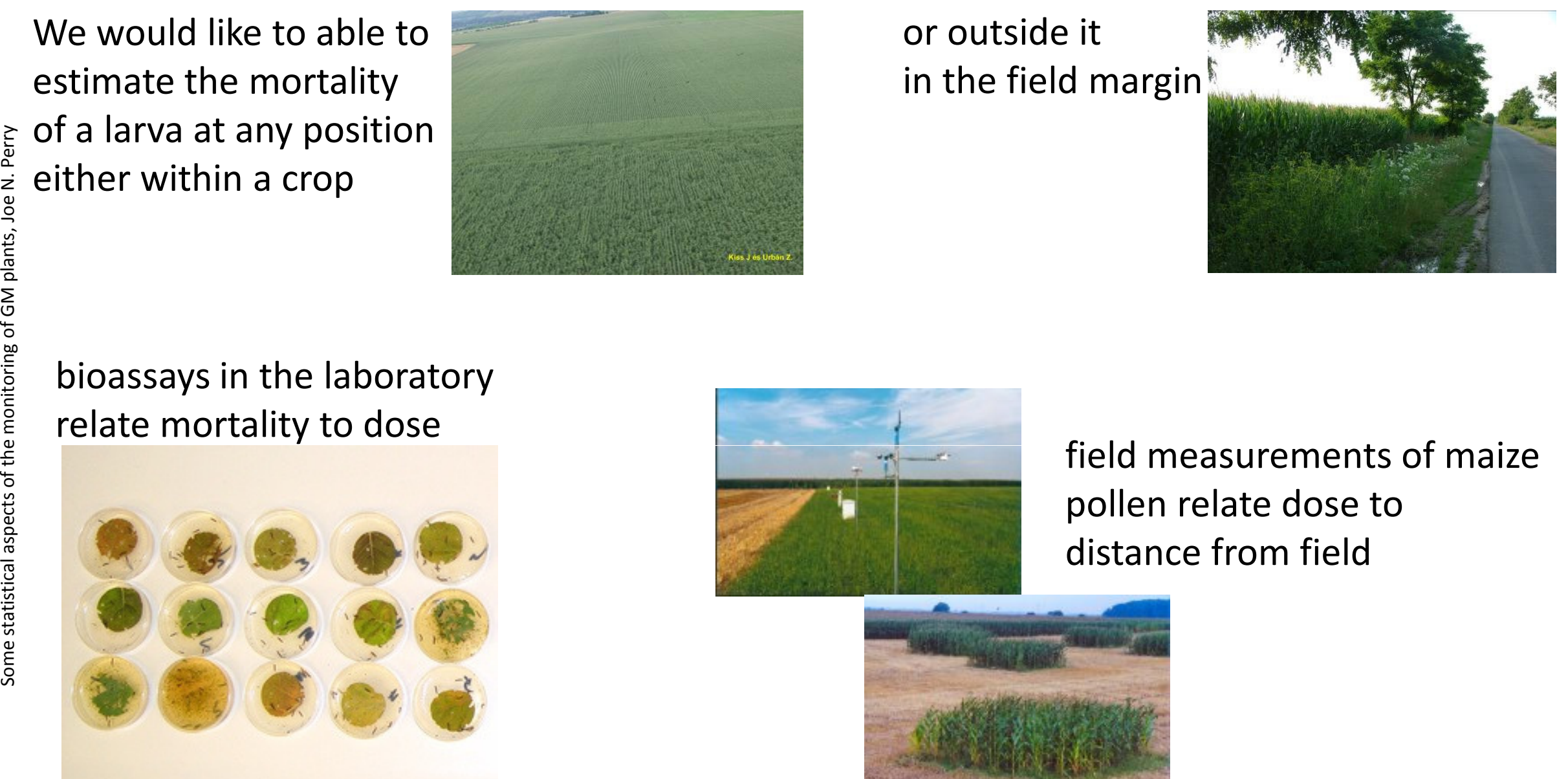

bioassays in the laboratory relate mortality to dose

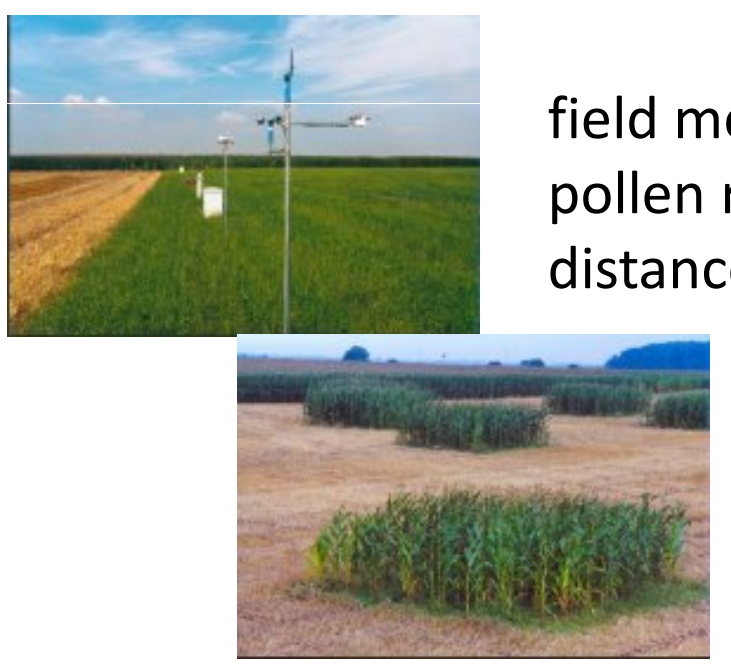

Can we combine these two common sources of information to obtain a relationship between mortality and distance? 


\section{Overview of new approach - mathematical}

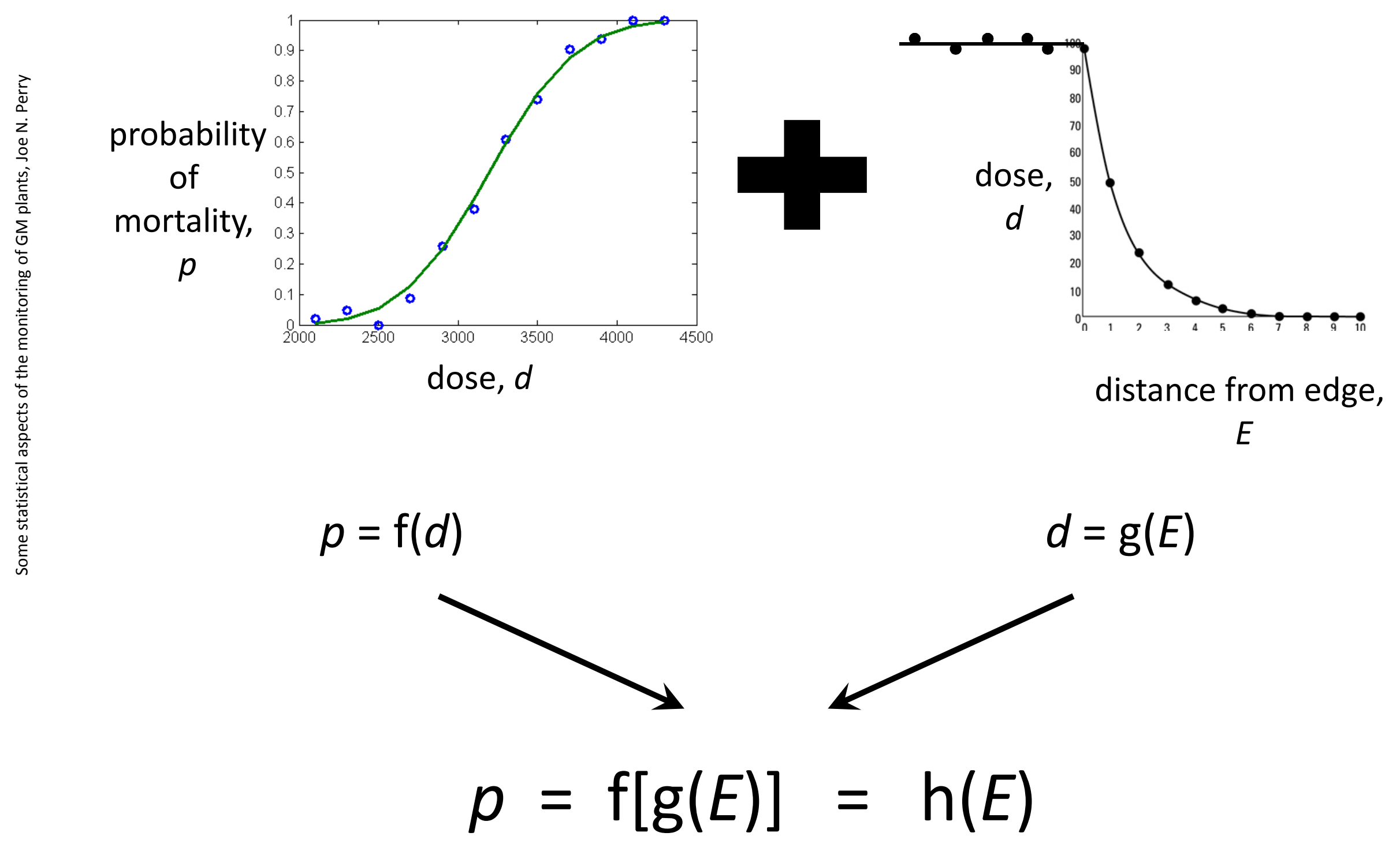




\section{Calculation of 'worst-case' mortality}

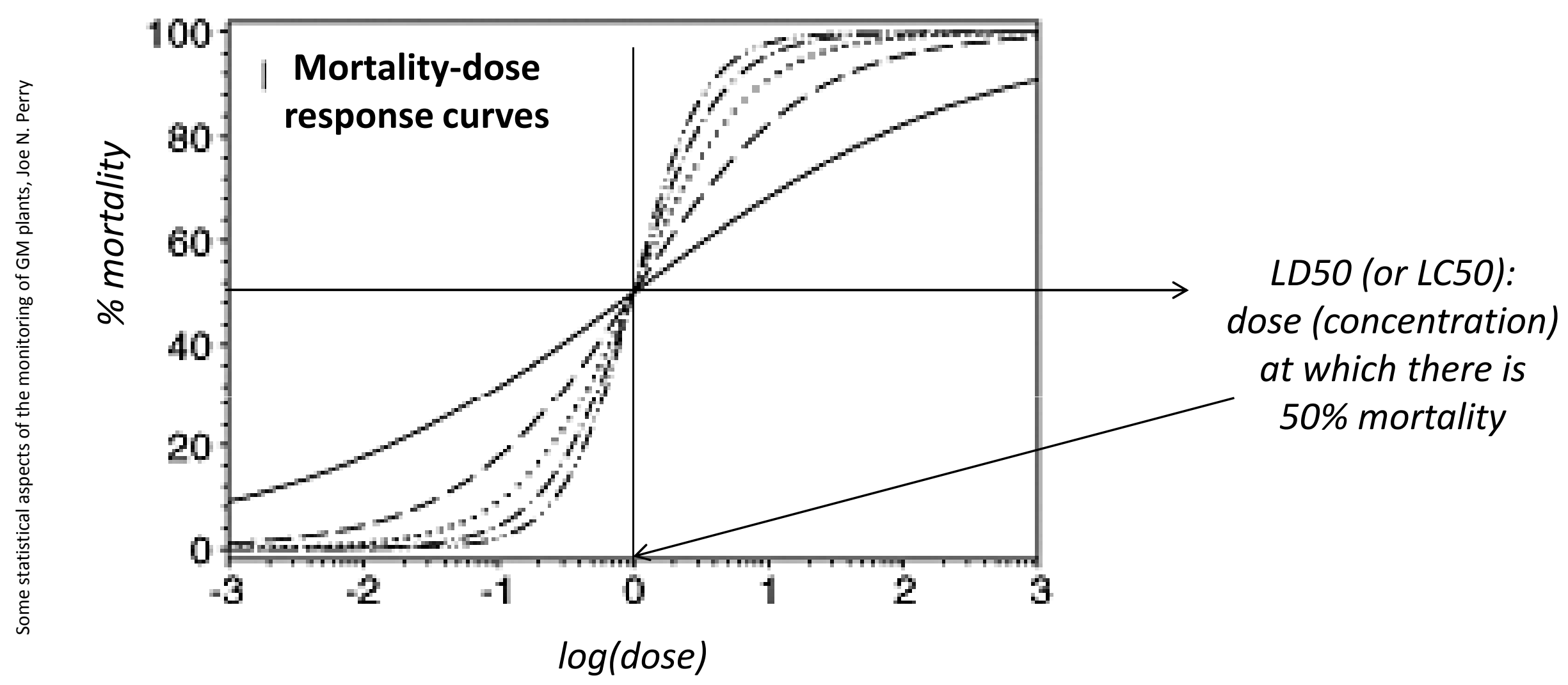

Different sigmoid curves show differing increase in mortality with increase of dose 


\section{Mortality-dose regression lines}

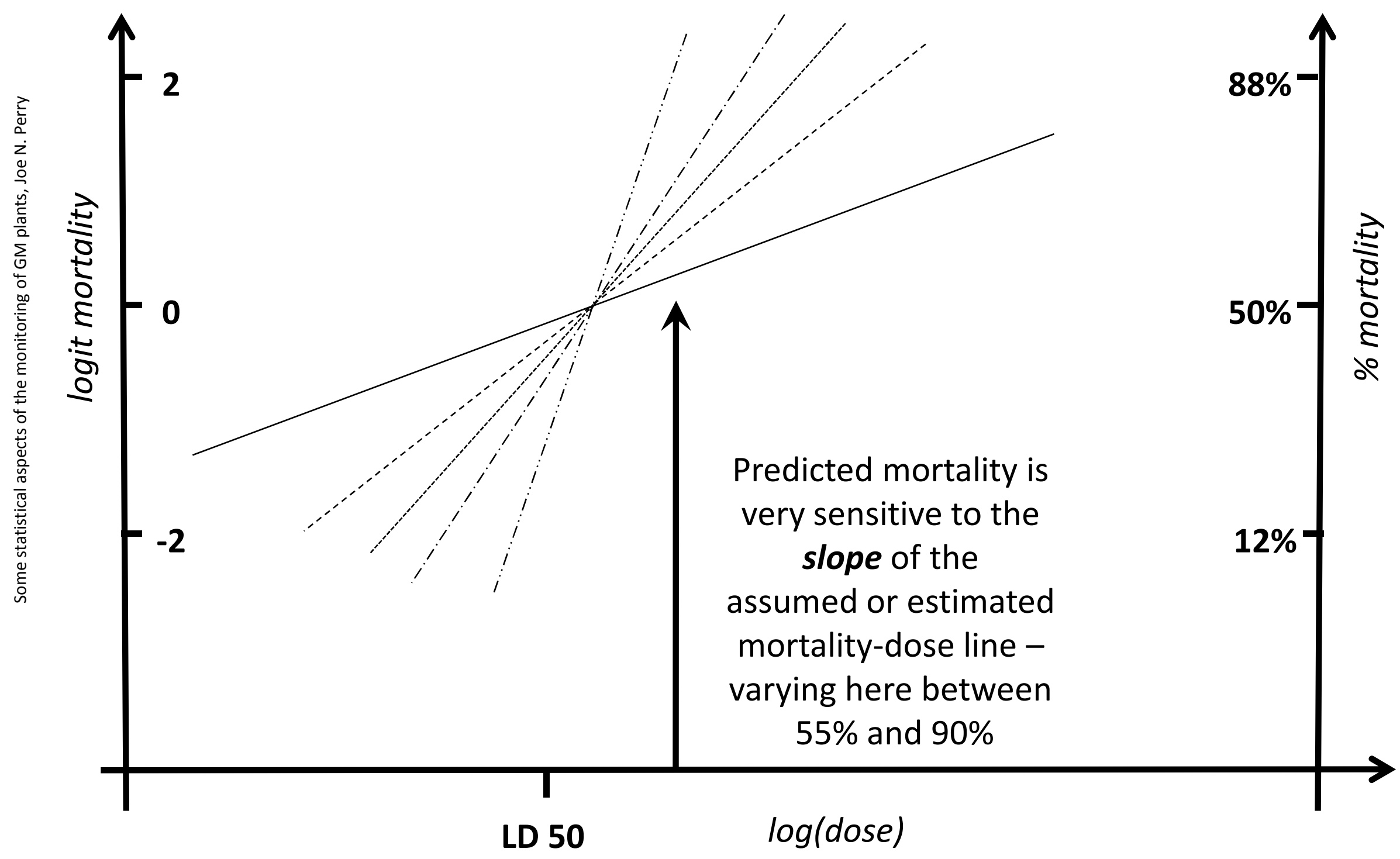




\section{Dose-distance relationships}

relating $d$, dose, to $E$, distance from edge of field

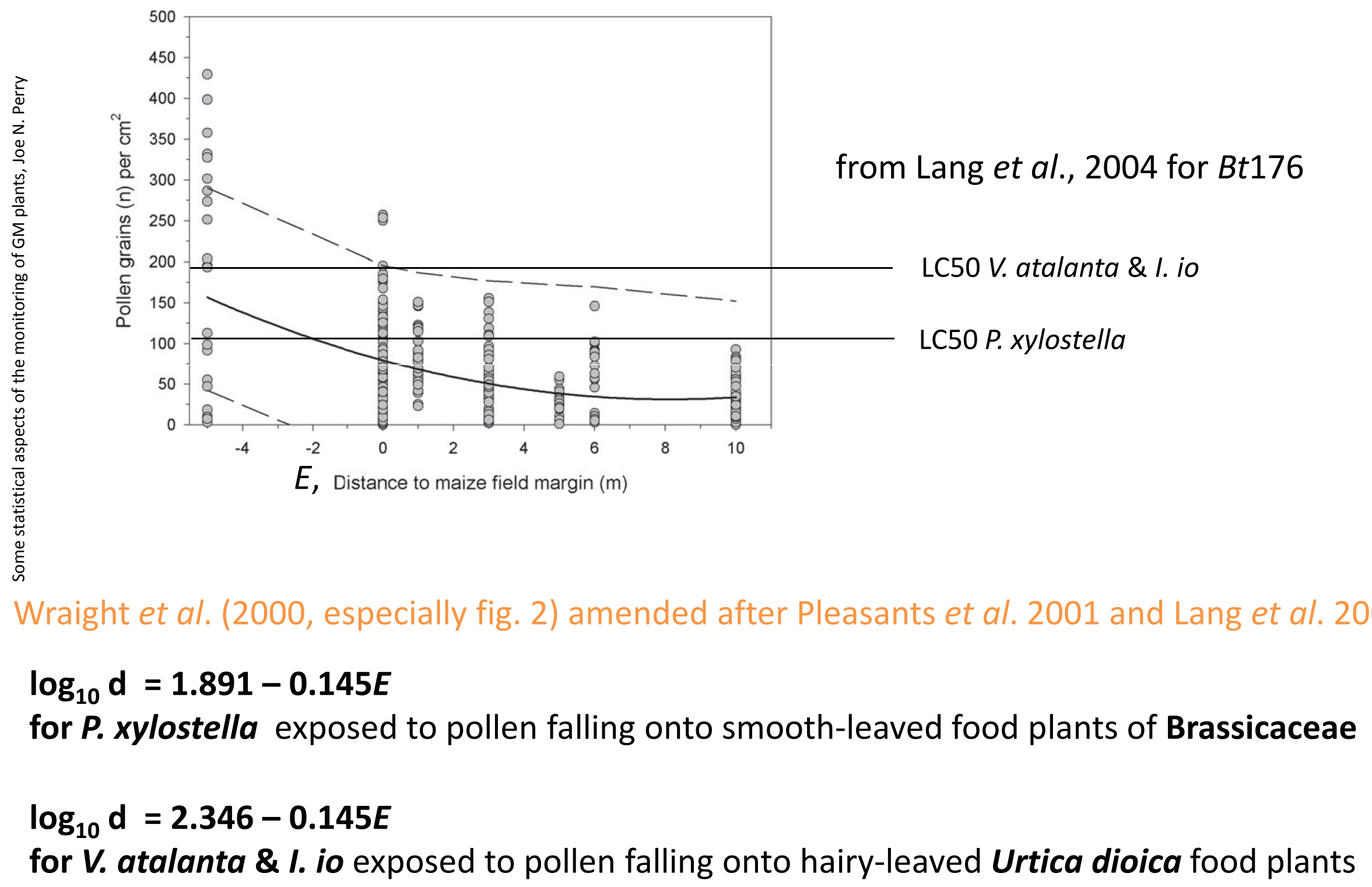




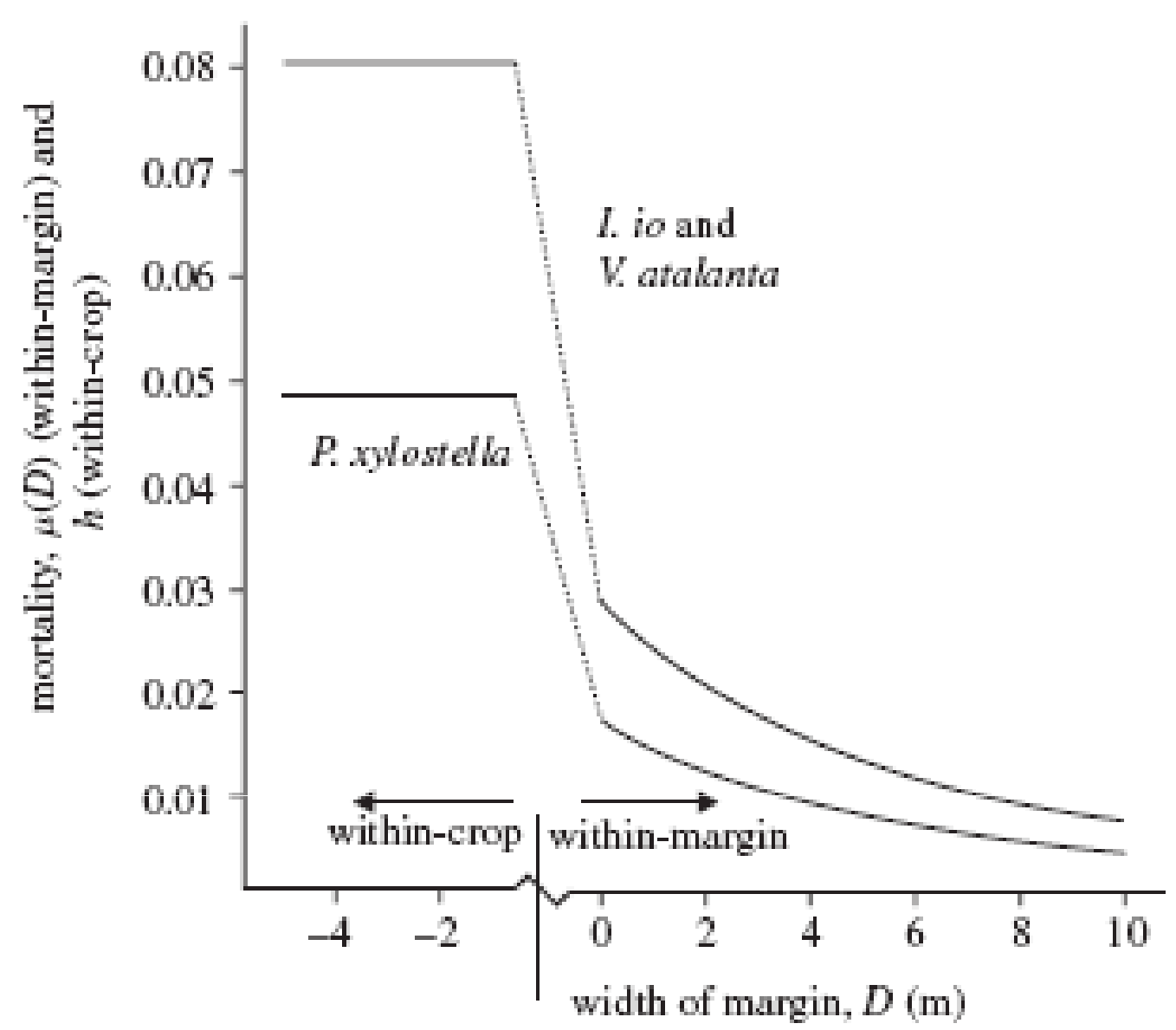

Figure 1. Estimated values of the parameter values $h$ (worstcase within-crop mortality, assumed constant ower the crop) and $\mu(D)$ (worst-case average mortality within a field margin of width $D$ metres, declining with $D$ ) for the butterflies $I$. io and $V$ atalanta and the moth $R$ xylostlla. Here, the term worst-case refers to potential mortality, as measured in the laboratory or under controlled conditions, before allowance for factors such as physical effects and temporal coincidence, and as opposed to more realistic values observed in the field 


\section{Parameter values}

Table 1. Parameter values used in the model. (Values given within curly brackets $\{,$,$\} are, respectively, the number of regions$ considered, and the minimum, maximum and median of authors' estimates across regions. For parameter $v$, values for nine of 11 regions (all those outside Spain) were set at 0.8 , to model the worst-case scenario for potential uptake, defined as that which gives maximal predictions of mortality.)

\begin{tabular}{|c|c|c|c|c|c|}
\hline parameter & type (units) & $\begin{array}{l}\text { species } I . \text { io on } \\
\text { U. dioica }\end{array}$ & $\begin{array}{l}\text { V. atalanta on } \\
U \text {. dioica }\end{array}$ & $\begin{array}{l}\text { P. xylostella on } \\
\text { Brassicaceae }\end{array}$ & give " $\mathrm{k}$ \\
\hline margin mortality, $g(E)$ & probability $(-)$ & equation (2.5) & equation (2.5) & equation (2.6) & \\
\hline within-crop mortality, $h$ & probability $(-)$ & 0.0805 & 0.0805 & 0.148 & \\
\hline physical effects, $x^{\mathrm{a}}$ & proportion $(-)$ & $\{10,0.2,0.8,0.4\}$ & $\{10,0.1,0.7,0.4\}$ & $\{11,0.1,0.8,0.5\}$ & \\
\hline temporal coincidence, $a^{\mathrm{a}}$ & proportion $(-)$ & $\{10,0.01,0.6,0.5\}$ & $\{10,0.01,0.6,0.5\}$ & $\{11,0.1,0.8,0.5\}$ & lar \\
\hline maize cropping, $z^{\mathrm{a}}$ & proportion $(-)$ & & $\{11,0.024,0.7,0.2\}$ & & lar \\
\hline utilization rate, $v^{\mathrm{a}}$ & proportion $(-)$ & & $\{11,0.035,0.8,0.8\}$ & & $\operatorname{lar}$ \\
\hline host plant in arable, $y^{\mathrm{a}}$ & proportion $(-)$ & $\{11,0.1,0.5,0.23\}$ & $\{11,0.1,0.5,0.23\}$ & $\{11,0.1,0.8,0.5\}$ & large \\
\hline host plant within-crop, $e^{\mathrm{a}}$ & density $\left(\mathrm{m}^{-2}\right)$ & $\{11,0,0.01,0\}$ & $\{11,0,0.01,0\}$ & $\{11,0,0.5,0\}$ & \\
\hline host plant in margin, $f^{\text {a }}$ & density $\left(\mathrm{m}^{-2}\right)$ & $\{11,0,10.0,0.5\}$ & $\{11,0,10.0,0.5\}$ & $\{11,0,15.0,0.5\}$ & \\
\hline size of maize fields, $C^{\mathrm{a}}$ & area $(\mathrm{ha})$ & & $\{11,1.1,58.0,15.0\}$ & & \\
\hline width of margin, $D^{\mathrm{a}}$ & distance (m) & & $\{11,1.0,4.5,2.0\}$ & & \\
\hline
\end{tabular}

${ }^{a}$ All parameters vary regionally and were estimated by authors. 


\section{Summary of results}

Table 2. Estimated population mortality rates. (For the butterflies, I. io and V. atalanta, the computed nd median values exclude Spain.)

\begin{tabular}{|c|c|c|c|}
\hline \multirow[b]{2}{*}{ region } & \multicolumn{3}{|l|}{ mortality } \\
\hline & I. io & V. atalanta & P. xylostella \\
\hline Bonn & $2.95 \times 10^{-5}$ & $2.95 \times 10^{-5}$ & $6.11 \times 10^{-5}$ \\
\hline Oderbruch & $5.03 \times 10^{-5}$ & $5.03 \times 10^{-5}$ & $6.16 \times 10^{-5}$ \\
\hline Aachen & $1.68 \times 10^{-4}$ & $1.68 \times 10^{-4}$ & $6.16 \times 10^{-6}$ \\
\hline Berkatal & $2.32 \times 10^{-4}$ & $2.32 \times 10^{-4}$ & $3.04 \times 10^{-4}$ \\
\hline Grebbin & $6.36 \times 10^{-4}$ & $6.36 \times 10^{-4}$ & $7.69 \times 10^{-4}$ \\
\hline Upper Rhine Valley & $4.40 \times 10^{-4}$ & $4.40 \times 10^{-4}$ & $2.55 \times 10^{-3}$ \\
\hline Tolna County & $1.91 \times 10^{-5}$ & $9.57 \times 10^{-6}$ & $1.53 \times 10^{-4}$ \\
\hline Po Valley (central) & $4.06 \times 10^{-4}$ & $3.55 \times 10^{-4}$ & $9.79 \times 10^{-4}$ \\
\hline Po Valley (coastal) & - & - & $5.13 \times 10^{-5}$ \\
\hline Madrid & 0 & 0 & $1.00 \times 10^{-9}$ \\
\hline Ebro Valley & 0 & 0 & $2.30 \times 10^{-\varepsilon}$ \\
\hline minimum over regions & $1.91 \times 10^{-5}$ & $9.57 \times 10^{-6}$ & $1.00 \times 10^{-9}$ \\
\hline maximum over regions & $6.36 \times 10^{-4}$ & $6.36 \times 10^{-4}$ & $2.55 \times 10^{-3}$ \\
\hline median over regions & $2.00 \times 10^{-4}$ & $2.00 \times 10^{-4}$ & $2.29 \times 10^{-4}$ \\
\hline
\end{tabular}




\section{Heterogeneity of pollen deposition}

\section{(Hofmann, 2007)}

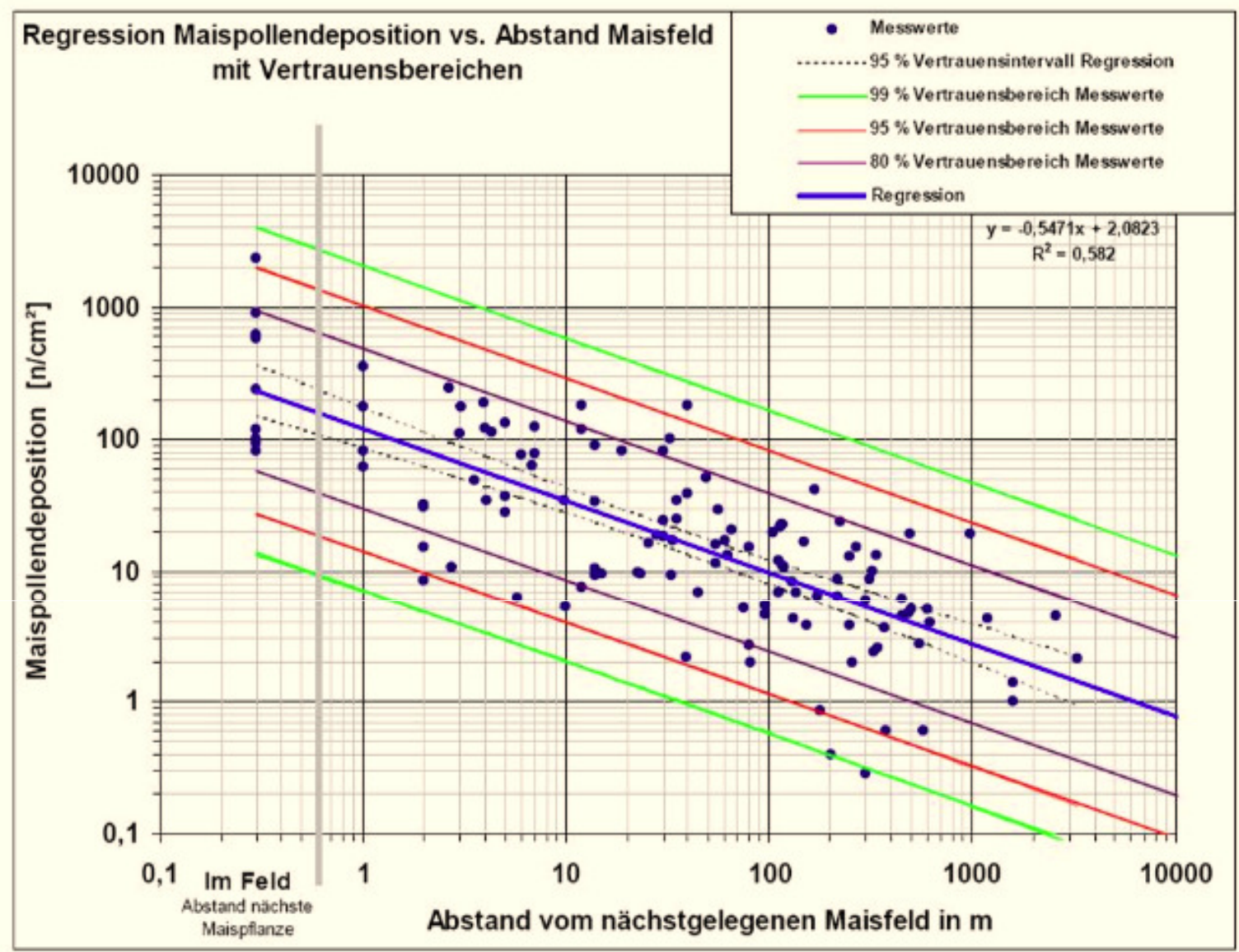

$\log _{10} d$ is shown to decline linearly with $\log _{10} E$, as expected, but with variability about the regression line that may be represented by a normal random variable with variance about 0.175 , so that the $99 \%$ confidence interval around the line encompasses about 12 -fold variation in concentration, at any given distance, in both directions. For linear systems, the average expected effect of such variation would be zero, 


\section{Conclusions}

1) Relationships between mortality and dose and between dose and distance may be integrated to estimate mortality both a crop within the field margin at varying

distances from the crop edge.

2) A full exposure assessment is possible for several Lepidopteran species

3) Many factors must be accounted for, some of which must be modelled with relatively little data. This results in uncertainty in estimated mortality and sublethality, which is compounded by natural variation between areas and differences between experts' interpretation.

4) However, even in the worst-case scenarios, in all areas considered, the estimate for mortality was less than one individual in every 1500, and of sub-lethality was less than one individual in $\mathbf{3 9 0}$, for the two butterfly species

5) For all the areas considered, the estimate for mortality was less than one individual in every 390 , and of sub-lethality was less than one individual in 95 , for the pest moth species. 


\section{Conclusions (continued)}

6) These estimates were made under the worst-case scenario of minimal probit slope and maximum uptake of MON810 maize by growers for the areas in Germany, Hungary and Italy.

7) Allowing for heterogeneity of pollen resulted in slight increases in estimated mortality, which were 1.33 times the corresponding deterministic value for $I$. io and V. Atalanta and 1.17 times for P. xylostella.

8) The amounts of MON810 pollen grains found in and around maize fields are unlikely to adversely affect a significant proportion of non-target lepidopteran larvae, after allowing for spatial heterogeneity of pollen deposition.

9) But data are required to reduce the uncertainty of the estimates reported here. 


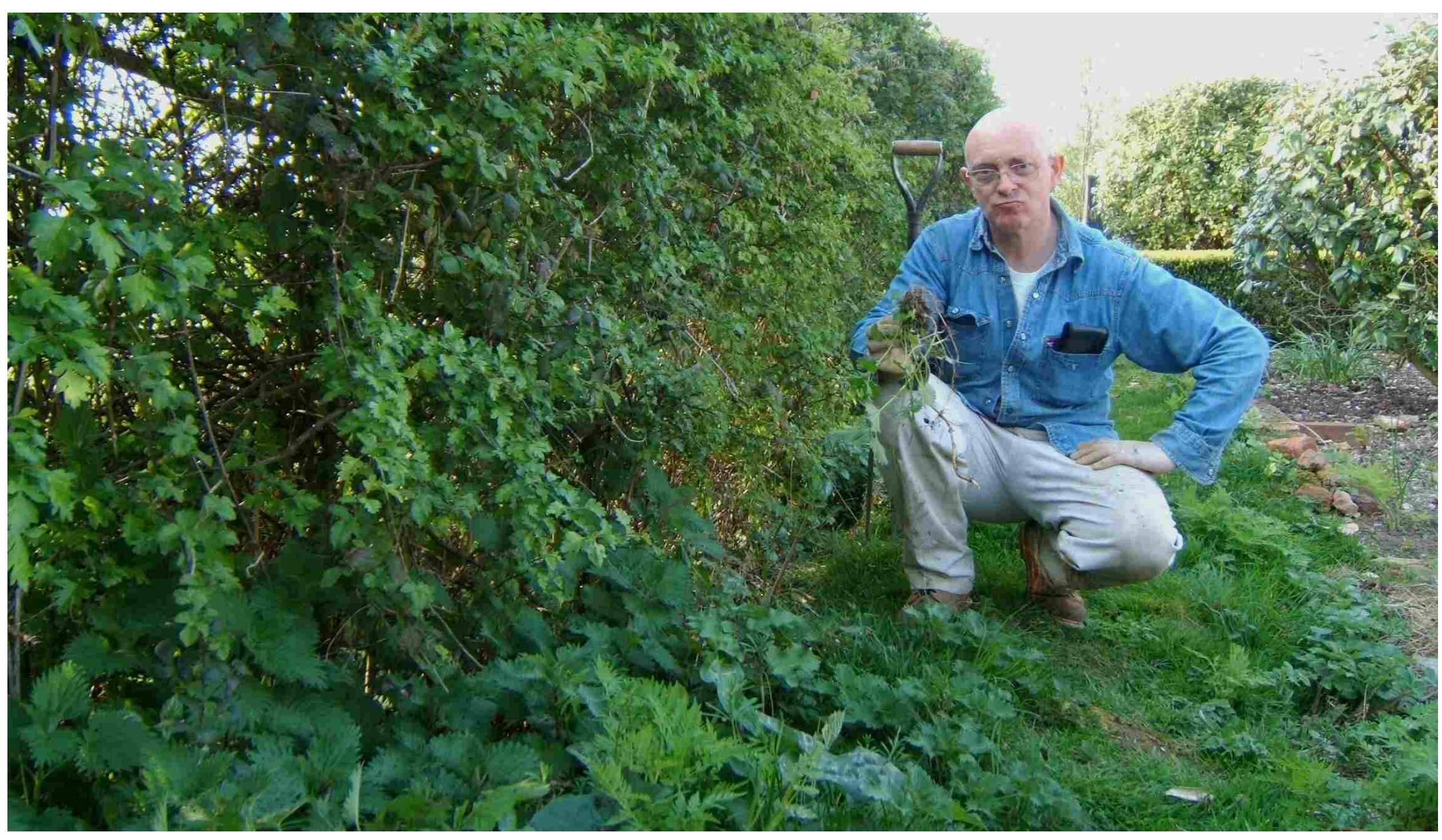

